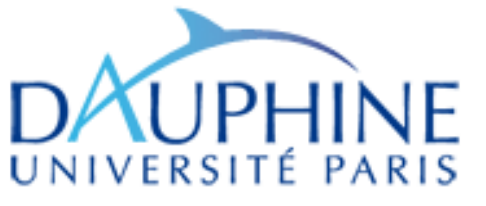

$\mathrm{D}$

I $\underset{\text { ment Instituitions \& mondialisation }}{\mathrm{L}}$

UMR 225 IRD - Paris-Dauphine
Institut de recherche pour le développement

\title{
Does poverty trap rural Malagasy households?
}

\section{Frédéric GASPART}

Anne-Claire THOMAS 


\title{
DOES POVERTY TRAP RURAL MALAGASY HOUSEHOLDS?
}

\author{
Frédéric Gaspart \\ Earth and Life Institute, \\ Université catholique de Louvain \\ Anne-Claire Thomas \\ UMR 225 DIAL, IRD, Université Paris Dauphine, \\ Earth and Life Institute, \\ Université catholique de Louvain
}

Document de travail UMR DIAL

Juillet 2012

\begin{abstract}
This paper studies the determinants of poverty dynamics in several rural areas from Madagascar. A particular attention is devoted to testing if rural poverty persistence in Madagascar could be explained by a vicious circle leading to a poverty trap. Annual poverty transitions retrieved from an original household panel data survey covering the 1996-2006 periods show that differences in household and environment characteristics are clearly associated with diperences in poverty transitions probabilities. Poverty-vulnerable households have higher dependency ratio and are less educated. They also show different income-generating activities pattern. They cultivate less market-oriented crops and have more vulnerable activities such as agricultural wage work. A Markovian poverty transition model is used to evaluate the role of past poverty in this situation. Past poverty is allowed to have both an intercept and a slope effect on poverty transitions probabilities. Our results show that a substantial share of the dixerences in household poverty transitions probabilities is attributable to past poverty status. These results encourage the development of social protection to prevent households to fall into a poverty trap as well as speciffic measures to encourage paths out of poverty traps.
\end{abstract}

Keywords: Poverty dynamics, state dependence, panel data, rural Madagascar.

\section{Résumé}

Cet article étudie les déterminants de la dynamique de la pauvreté dans plusieurs zones rurales de Madagascar. Une attention particulière est portée à l'identification d'un éventuel effet délétère de la pauvreté passée sur la pauvreté future pouvant conduire à un cercle vicieux de perpétuation de la pauvreté. Le papier se base sur l'étude des transitions annuelles sur et sous le seuil de pauvreté observées sur un panel de ménages ruraux malgaches entre 1996 et 2006. Un modèle markovien est utilisé pour évaluer le rôle des caractéristiques des ménages, de l'environnement et de la pauvreté passée dans la probabilité de passer sur ou sous le seuil de pauvreté. Les résultats montrent que certaines caractéristiques des ménages et de l'environnement sont clairement associées à différences dans les probabilités de transitions sur et sous le seuil de pauvreté. En particulier, les ménages vulnérables à la pauvreté ont un rapport de dépendance plus élevé, sont moins éduqués et ont une composition de revenus différentes. Ils sont notamment moins orientés vers les cultures agricoles et plus orientés vers des activités précaires comme le salariat agricole. Un effet délétère de la pauvreté passée sur le risque d'être pauvre dans le futur est également mis en évidence. Il passe à la fois par un effet de pente et un effet de niveau. Ces résultats soulignent la nécessite de mettre en place des politiques spécifiques contre la vulnérabilité à la pauvreté, d'une part, et contre la pauvreté de long terme d' autre part.

Mots Clés : Dynamique de la pauvreté, state dependence, données longitudinales, Madagascar

JEL Codes : C01, C33, C34, O12 


\section{Introduction}

In Madagascar, more than three-quarters of the rural population live below the poverty line. This proportion has remained constant since the late nineties despite sustained national output growth and a substantial decrease in urban poverty (WorldBank, 2011). Poverty reduction is a clear policy objective in Madagascar since the beginning of the 2000s 1 However, poverty reduction has not come up to expectations, especially in rural areas. Rural poverty rates have remained around $75 \%$ since the 1990s. Appropriate poverty reduction policies in rural Madagascar require more knowledge on the nature and causes of poverty. It is crucial to understand what incentives could shape household behaviours towards more profitable livelihood strategies and therefore, poverty exit.

There is now a wide acceptance that static analyses have limited explanatory power and may conceal the processes that are central to the persistence of poverty and its reduction (Addison et al., 2009). Static analyses indeed consider the poor as a fixed group with permanent characteristics as if its composition does not change over time. Dynamic analysis of poverty highlights considerable mobility across the poverty line. Actually, two types of poverty can be distinguished: chronic and transient poverty. Particular attention should be devoted to poverty durations and its determinants for two main reasons. First, chronic poverty is usually considered as more serious. There is a simple logic that says that if one person has experienced the same forms and depths of poverty as another, but for a much longer period, there is an ethical imperative to support the former (Baulch, 2011). Second, if chronic and transient poverty have different determinants, efficient targeting of one form of poverty or the other requires different tools.

In particular, the role of past poverty on current poverty risk is a crucial element to be identified. It is now widely established that households who experience poverty once are more likely to experience poverty again in the future. Two mechanisms may explain this phenomenon. First, some household intrinsic characteristics can make them more vulnerable to poverty. This mechanism is called the individual heterogeneity mechanism. A low education, a large number of dependents or a limited social network, for example, increase the likelihood of being poor. Unobserved characteristics such as low intelligence also play a role. If these characteristics persist over time, it creates a "spurious" correlation between past and future poverty. Second, poverty can have a true causal effect on future poverty. This mechanism is called the state dependence mechanism. The very fact of being poor may lead to an increase in the probability of being poor in the future. In this case, two initially identical households have different poverty risk depending of their past poverty experience. This last possibility seems plausible in the context of rural Madagascar since the opportunities to borrow, save or insure are very low. When falling in poverty, a poor

\footnotetext{
${ }^{1}$ Madagascar participates in the Heavily Indebted Poor Countries (HIPC) Initiative for debt relief. Conditional on implementing a poverty reduction strategy written down in a Poverty Reduction Strategy Paper, the World Bank and the International Monetary Found accord to Heavily Indebted Poor Countries financial assistance and debt reductions.
} 
household is often forced to liquidate its productive assets to maintain consumption at a reasonable level, thereby reducing the prospects of future income. Poverty can also lead to loss of motivation, social exclusion or health problems that reduce the potential for future revenue and make the household more likely to be poor. In addition, poverty may motivate risk averse behaviours that hinder long-term welfare perspectives. For example, Gubert and Robilliard (2008) have shown that taking children out of school is part of the risk-coping strategies in Madagascar. In terms of economic policy, the first mechanism calls for anti-poverty policies that address household characteristics that make them vulnerable to poverty. If poverty is associated with low education level, high dependency ratio and social exclusion, policies should increase education level, encourage family planning, provide allocations for the dependents and give information, support or any service usually provided by social relations. The second mechanism calls for tools that prevent households from falling below the poverty line when facing an income loss or any temporary hardship. Tools to limit the duration spent below the poverty line are also deeply needed. It namely involves social transfers or the granting of credits. To go further, identifying through which mechanisms past poverty increases future poverty should provide useful information to break poverty traps.

This paper makes a attempt to measure state dependence, i.e. the impact of past poverty on current poverty risk. We examine poverty dynamics thanks to observed poverty transitions in several rural areas of Madagascar. The following section briefly reviews the economic literature on state dependence in poverty dynamics and places our work in this context. The third section presents the econometric model and estimation method. The fourth section presents data and describes poverty dynamics in the studied areas. The fifth section presents the results and the sixth section concludes.

\section{Evidence of state dependence in poverty dynamics.}

\subsection{Methodological considerations: which data and models are suitable for studying poverty dynamics?}

The growing availability of households panel data in developing countries has lead to the development of a large literature on poverty dynamics. When the same households are followed during a given period, it is possible to refine the group of poor households into more categories depending on the duration they have spent below the poverty line. Chronic and transient forms of poverty can then be distinguished. Baulch and Hoddinott's pioneer book (Baulch and Hodinott, 2000) about poverty dynamics in developing countries contains six case studies drawing from the very limited number of panel household surveys that were then available. Since then the number of papers has grown exponentially so that it is impossible to review the whole literature. Good reviews on selected recent papers are Dercon and Shapiro (2007) and Baulch (2011).

Despite this large literature, empirical work on poverty dynamics is still constrained 
by data limitations. Most of the available household panel surveys in developing countries only contain two or three observation points. Identification of poverty dynamics is thus often questionable either because the survey period is too short or because the observation points are too far away in time. To fill this gap, Baulch (2011) among others collects studies drawn for panel datasets that cover longer periods. In this paper, we use a original panel data survey from Madagascar that provides annual household data during two to eleven years depending on the area. It is thus quite well suited to study poverty dynamics at least when compared with data usually available in developing countries.

Three main approaches can be found in the literature on poverty dynamics: the 'component' approach, the 'spell' approach, as called by Yaqub (2000), and the Markovian transition approach. The different approaches imply different assumptions regarding the dynamic process underlying observed poverty status outcomes over time.

The component approach proposed by Jalan and Ravallion (1998) summarizes individual living standard trajectories into individual chronic and a transient poverty component. The chronic component of poverty is the poverty level that would have been observed if intertemporal variability of consumption have been smoothed out. Basically, chronic poverty is calculated be entering the intertemporal average of consumption in classical FGT poverty indexes. The transient component of poverty is the contribution of consumption variability to observed poverty. It is calculated as a residual equal to the difference between the intertemporal average of poverty observed over the period as measured by classical FGT indexes and chronic poverty. This method implies strong assumptions on aggregation of welfare over time (Calvo and Dercon, 2007) 2 Moreover, because this method aggregates individual welfare trajectories into a single individual measure of chronic (or transient) poverty, it does not allow to identify state dependence in poverty dynamics.

The spell approach (Bane and Ellwood, 1986; Stevens, 1999) studies durations of poverty spells and probabilities that a poverty spell ends. By contrast to the component approach, the spell approach is truly dynamic. The hazard, i.e. the instantaneous probability of leaving poverty at period $t$ given that the household has not already left poverty, is specified as a function of the characteristics of households and the duration of past poverty. The latest versions of hazard models (also called duration models) take into account multiple episodes of poverty and unobserved heterogeneity. Hazard models are very well suited to study the impact of past poverty on current poverty. Poverty duration indeed explicitly

\footnotetext{
${ }^{2}$ This method uses the intertemporal average of income or consumption to summarize households' living standards. Poverty spells are thus assumed to be compensated by non-poverty spells. In other words, a given consumption fall under the poverty line at a point in time is offset by a consumption increase by the same amount above the poverty line at any other point in time. This hypothesis is very unlikely, especially in rural areas of developing countries where liquidity constraints are strong and insurance and credit possibilities very limited. In addition, the chronic poverty measure used in the component approach does not explicitly consider the time spent under the poverty line. To take an extreme case, an household will be considered chronically poor if he spent the entire period of observation slightly above the poverty line but faces a serious income drop during a single year, so that the average intertemporal consumption is below the poverty line.
} 
enters the statistical model. Since both households characteristics and duration of past poverty spells enter the model, it convincingly tests the two mechanisms behind poverty persistence mentioned in the introduction, i.e., the individual heterogeneity and state dependence mechanisms.

In practice, some problems arise though. Essentially, introduction of unobserved heterogeneity in hazard models leads to an issue regarding the treatment of (endogenous) initial conditions. If the model is true and that an individual time-invariant variable affects poverty propensity, the first observed individual's poverty status is no longer random. Individuals with a high poverty propensity are more likely to be found in poverty at the start of the observation period. This issue requires very complex treatments that did not find a satisfactory answer until now (Jenkins and Rigg, 2001). Practically, the household initial poverty status is always considered exogenous. Besides, since households are observed for a finite period of time, poverty spells may have already begun in the first observation year (left censure) or still be under way in the last observation year (right censure). Right censored data are not a statistical problem if the censoring time is independent of poverty duration, i.e. for a sufficiently large sample. Otherwise, the censoring process has to be modelled jointly with poverty transitions. Left censored data are more problematic since duration that households have spent below the poverty line before the first year of observation cannot be determined. Usually left censored data are discarded. This leads to underestimating the persistence of poverty. In addition, it reduces the amount of data used for the estimation and therefore its accuracy. The observation period should be long enough to have enough variability in poverty durations to correctly identify its impact. This method is thus very demanding in data.

The third approach is to model annual transition probabilities as a first-order Markov chain. Compared to duration models, the dynamics is simpler since only first order dynamics is modeled. Poverty persistence are thus identified by two consecutive years (only) below the poverty line 3 To investigate poverty determinants, two types of models can be used: a random effect dynamic probit (REDP), that writes as follows:

$$
P\left(p_{i t}=1 \mid p_{i, t-1}, x_{i}, e_{i}\right)=\Phi\left(x_{i t}^{\prime} \beta+\rho p_{i, t-1}+e_{i}\right)
$$

or an endogenous switching probit model (ESPM), that writes as follows:

$$
\begin{gathered}
\left.P\left(p_{i t}=1 \mid p_{i, t-1}, x_{i}, e_{i}\right)=\Phi\left(\left[p_{i, t-1} \beta_{1}+\left(1-p_{i, t-1}\right) \beta_{2}\right] x_{i t}^{\prime}+e_{i}\right)\right] \\
P\left(p_{i, t-1}=1 \mid z_{i}, e_{i}^{s}\right)=\Phi\left(z_{i t-1}^{\prime} \beta^{s}+f_{i}\right)
\end{gathered}
$$

\footnotetext{
${ }^{3}$ Increasing the order of the dynamics is of course possible. Statistical treatment of the data is however more complex.
} 
where $p_{i t}$ equals one if household $i$ is poor at time $t$. The $x_{i t}$ vector is a vector of time varying exogenous variables that explains the probability of being poor at time $t$. The parameter $e_{i}$ is an household time-invariant effect independent of $x_{i t}$. The function $\Phi$ usually is the distribution function of the normal distribution. Equation (3), in the ESPM, describes poverty status in the base year. It describes "initial conditions" using a reduced form approach, analogous to that proposed by Heckman (1981). The vector $z_{i t-1}$ is a vector of time varying exogenous variables and $f_{i}$ is an household time-invariant effect.

The ESPM specification is namely used in Cappellari (2007) to study low income transition in UK. The REDP specification is used in Cappellari and Jenkins (2008) to study the dynamics of social assistance receipts in the United Kingdom. Both models address the issues of unobserved persistent individual heterogeneity, endogeneity of initial conditions and state dependence.

Unobserved persistent individual heterogeneity in transition probabilities is addressed by the household time-invariant effect.

Endogeneity of initial conditions is addressed by equation (3) in the ESPM. In the REDP, several approaches are possible. The most frequent is to specify first year poverty status by a reduced form linear approximation as proposed by Heckman (1981). Two steps procedures are also possible (Orme, 1997). Another approach, used in this paper, is the conditional maximum likelihood estimator proposed by Wooldridge (2005).

Regarding state dependence, poverty status is allowed to depend on past poverty directly in the REDP model and through interactions with explanatory variables in the ESPM. True state dependence can be convincingly tested in both models since households and environment characteristics contained in $x_{i t}$ and $e_{i}$ control for other sources of poverty persistence than past poverty. The causal effect of past poverty on future poverty is measured by the impact of the lagged poverty status in the REDP whereas it is measured by the difference between the impact of explanatory variables, according to whether the household was poor in $t-1$ or not, in the ESPM.

These two models are complements rather than substitutes to duration models. The main advantage of the transition approach is the possibility to allow for endogenous initial poverty status. Moreover, the specification is flexible and the model easy to estimate. Data needs are smaller since poverty durations are not needed. Moreover, we do not face issues related to left censored durations. In our case study where around $70 \%$ of the sample is poor in the first observation period, it is a significant advantage. The choice between REDP and ESPM depends on the assumption about the way poverty is assumed to affect current transition probabilities, either through a change in the intercept in the REDP or through a change in the impact of household characteristics on the probability to be poor in the ESPM model.

It may be worth noting that a different type of dependence on past poverty is identified in the spell and Markovian approach. It is tested if poverty status at time $t$ depends on poverty status at an earlier period in the latest and on the length of time spent in poverty in the last. Devicienti (2002) refers to state dependence and duration dependence 
to distinguish between these two concepts.

\subsection{Evidence of state dependence in poverty dynamics in rural Mada- gascar}

Whereas substantial quantitative corroborative evidence show that an individual that was poor in the past is much more likely to be poor in the future in OECD countries (Biewen, 2009; Duncan, 1993; Giraldo et al., 2002; Oxley et al., 2000), such studies are not common in developing countries settings. As explained in the preceding section, methods to measure state dependence are very demanding in data that are seldom available in developing countries. To our knowledge, the REDP model has only been applied by Alem (2011) and Islam and Shimless (2007) to study state dependency in poverty in Ethiopia. The ESPM is used by Fave et al. (2011) and Ribas et al. (2006) to study poverty in Nairobi slums and in Brazil respectively. They all find strong evidence of state dependence in their data.

In rural Madagascar, studies on state dependence are few. Existing studies on poverty have mostly been static (Droy et al., 2010) or, when dynamics, focused on households and environment determinants rather than state dependence (Gubert and Robilliard, 2003; Gondard-Delcroix, 2005). Several studies also consider specific aspects of poverty like agricultural productivity, infrastructures, risk, etc. Gubert and Robilliard (2003) use a hazard model framework to identify the correlates of poverty exit and re-entry in four rural areas of Madagascar over the period 1996-2002. They find that poverty is due to household characteristics rather than a causal effect of past poverty, rejecting duration dependence. However, these results have to be taken with caution for two reasons. First, left censored spells are ignored so that poverty persistence is understated. Second, unobserved heterogeneity is not controlled for. Ignoring unobserved heterogeneity can lead to underestimating how the hazard rate changes with duration and overstating the effect of the covariates on the hazard rate (Lancaster, 1990).

Evidence argues in favour of state dependence in rural Madagascar trough at least three channels. First, poverty leads to use asset selling as an insurance strategy (Barrett et al., 2006). To maintain consumption above an acceptable level, households are constrained to sell their productive assets. They therefore increase the probability to be poor in the future. Second, poverty may lead to lower participation in social network (Thomas, 2011, chap 4). By providing information and/or insurance, social networks usually help household to find opportunities to leave poverty. By participating less in social networks, poor households have reduced odds to leave poverty. Third, risk considerations have adverse consequences for the poor. On one hand, poverty means lower resilience against shocks because lower levels of assets and fewer insurance possibilities. On the other hand, poverty lead households to reduce their risk-exposure. Such a decision often mean trading expected return again reduced income volatility (Barrett et al., 2006; Gondard-Delcroix, 2009; Gubert and Robilliard, 2008; Thomas, 2011). 


\section{Methodology}

We apply the Markovian transition model to our Malagasy rural household data. We assume that poverty follows a first order Markov process. It implies that transition probabilities are independent of the poverty status previous to $t-1$ and namely of the duration spent in each poverty state.

The impact of past poverty on current poverty can be treated in different ways. The appropriate model depends on how one believes past poverty affects current poverty propensity.

If one believes that past poverty status has a slope effect, i.e., that the impacts of explanatory variables on current poverty differ according to past poverty status, then an endogenous switching regime model is required. To proceed, we split the sample into two groups: the poor at $t-1$ and the non-poor at $t-1$. We then estimate an equation for the current poverty status for each subsample accounting for the fact that each sample is a non-random sample of all households. According to this type of model, the past poverty status effect shows up in the fact that the coefficient of explanatory variables and the constant term may differ from the previously poor to the previously non-poor sample. The difference in the coefficient of explanatory variables tells how the returns to different observable attributes vary by initial poverty status. Essentially this model allows a full set of interaction terms between initial poverty status and the explanatory variables.

If one believes that previous poverty status has merely an intercept effect on current poverty status, then the appropriate model includes initial poverty status as a right-handside variable and pools the entire sample of previously poor and previously non-poor households. We obtain a dynamic random effect probit model.

These two models are treated one after the other in our analysis.

\subsection{Random Effect Dynamic Probit Model}

We first deal with the Random Effect Dynamic Probit Model (REDP). This method has namely been used to study state dependence in poverty history, social assistance receipt, low pay, low income and unemployment in developed countries (Biewen, 2009; Cappellari and Jenkins, 2008).

\subsubsection{Specification}

We consider a random effect dynamic probit model (Wooldridge, 2001):

$$
P\left(p_{i t}=1\right)=P\left(\theta_{1} p_{i t-1}+\delta^{\prime} g_{i t}+e_{i}+\varepsilon_{i t}>0\right)
$$

where $p_{i t}$ is the poverty status of household $i, i=1 \ldots N$ in period $t, t=1 \ldots T$ and $p_{i t-1}$ is the poverty status in the previous period $t-1$. The vector $g_{i t}$ is a vector of exogenous 
explanatory variables. The scalar $e_{i}$ is an (unobserved) household time invariant effect. It contains all household specific time invariant unobserved determinants of poverty like intelligence or motivation for instance. The residual $\varepsilon_{i t}$ is an error term assuming to follow a standard normal distribution.

\subsubsection{Estimation}

To estimate the model, we have to write the likelihood of the observed sample as a function of the parameter to estimate $(\theta, \delta)$. We can write:

$$
\begin{aligned}
f\left(p_{i 1}, \ldots, p_{i T} \mid p_{i 0}, g_{i}, e_{i} ; \theta, \delta\right)= & \prod_{t=1}^{T} f\left(p_{i t} \mid p_{i t-1}, . ., p_{i 0}, g_{i}, e_{i} ; \theta, \delta\right) \\
= & \prod_{t=1}^{T} f\left(p_{i t} \mid p_{i t-1}, g_{i t}, e_{i} ; \theta, \delta\right) \\
= & \prod_{t=1}^{T} \Phi\left(\delta^{\prime} g_{i t}+\theta_{1} p_{i t-1}+e_{i}\right)^{p_{i t}} \\
& {\left[1-\Phi\left(\delta^{\prime} g_{i t}+\theta_{1} p_{i t-1}+e_{i}\right)\right]^{1-p_{i t}} }
\end{aligned}
$$

To be able to write the second line of expression (5), we have to make the crucial assumption that explanatory variables in $g_{i t}$ are strictly exogenous. This assumption means that conditional on poverty status in the previous period and the unobserved heterogeneity, the poverty status at period $t$ is not related to the value of explanatory variables nor in the past nor in the future periods. In addition, we assume that poverty follows a first order Markov process and that only the first lag of poverty status is relevant for current poverty status in period $t$.

Because $e_{i}$ is unobserved, the final density in (5) does not allow us to construct a loglikelihood function leading to consistent estimates of $(\theta, \delta)$ with fixed T- asymptotics. This problem is known as the incidental parameter problem. To be able to estimate $(\theta, \delta)$, it is needed to integrate out the parameter $e_{i}$ in the density function (Wooldridge, 2005). Two issues arises.

First, $e_{i}$ is likely to be correlated with explanatory variables. For instance, the intelligence level is probably correlated with the education level. Second, we need to decide how to treat the initial observation $p_{i 0}$. This is usually called the initial condition problem. We follow Wooldridge (2001) and model household specific heterogeneity as follows:

$$
e_{i}=\Psi+\bar{x}_{i} \xi+\tau p_{i 0}+a_{i}
$$

with $\bar{x}_{i}=\frac{1}{T} \sum_{i=1, \ldots, T} x_{i t}$ and $a_{i} /\left(\bar{x}_{i}, p_{i 0}\right) \hookrightarrow \operatorname{Normal}\left(0, \sigma_{a}^{2}\right)$ and $\Psi, \xi, \tau$ parameters to be estimated Equation (4) can be rewritten : 


$$
p_{i t}=P\left(\delta^{\prime} x_{i t}+\theta p_{i t-1}+\Psi+\bar{x}_{i} \xi+\tau p_{i 0}+a_{i}+u_{1 i t}>0\right)
$$

By construction, $a_{i}$ is uncorrelated with the explanatory variables. In other words, the classical assumptions needed to consistently estimate $(\delta, \theta, \Psi, \xi, \tau)$ with random effects by conditional maximum likelihood are verified: strict exogeneity of explanatory variables, orthogonality between explanatory variables and the unobserved time invariant heterogeneity.

\subsubsection{Average partial effects}

Since our model is non-linear, partial effects of explanatory variables are not constant along the distribution of the explanatory variables. Moreover, the presence of unobserved heterogeneity $a_{i}$ raises the issue of which value to impute to $a_{i}$. Using the sample mean value is a possibility. It is equal to zero since $a_{i}$ follows a standardized normal distribution. However, this value corresponds to a very small fraction of the population. It makes more sense to estimate partial effects averaged on the whole distribution of $a_{i}$. The partial effect of $x_{j}$ averaged over the distribution of $a_{i}$ is consistently estimated by:

$$
\frac{\delta p_{i t}}{\delta x_{j}}=\hat{\delta}_{a} \frac{1}{N}\left[\sum_{i=1 \ldots N} \Phi\left(\hat{\delta}_{a}^{\prime}\left(x_{i t}\right)+\hat{\theta}_{a} p_{i t-1}+\hat{\Psi}_{a}+\bar{x}_{i} \hat{\xi}_{a}+\hat{\tau}_{a} p_{i 0}\right)\right]
$$

where the $a$ subscript means that parameter has been multiplied by $1 / \sqrt{\left(1+\sigma_{a}^{2}\right)}$ and $\left(\hat{\delta}, \hat{\theta}, \hat{\Psi}, \hat{\xi}, \hat{\tau}, \hat{\zeta}, \hat{\sigma}_{a}^{2}\right)$ are the estimators obtained from the maximization of the likelihood of equation (5).

\subsubsection{State dependence}

State dependency is measured by the partial effect of past poverty status. The average partial effect of $p_{i t-1}$ is consistently estimated by:

$$
\frac{\delta p_{i t}}{\delta x_{j}}=\hat{\theta}_{a} \frac{1}{N}\left[\sum_{i=1 \ldots N} \Phi\left(\hat{\delta}_{a}^{\prime}(x)+\hat{\theta}_{a} p_{i t-1}+\hat{\Psi}_{a}+\bar{x}_{i} \hat{\xi}_{a}+\hat{\tau}_{a} p_{i 0}\right)\right]
$$

\subsubsection{Limitations}

Under this estimation technique, the coefficients of the explanatory variables are restricted to be the same for poor and non-poor households. We thus measure the average effect of explanatory variable on the poverty risk. A analysis that allows a differential impact of explanatory variables on the poverty risk depending on the poverty status would be appropriate For instance, we know that the return on productive capital is lower for the poor because exclusion from insurance and credit markets maintain them in low risk-low return activities (Dercon and Christiaensen, 2011; Thomas, 2011). 


\subsection{Endogenous Switching Probit Model}

\subsubsection{Specification}

Poverty dynamics can also be modeled by an Endogenous Switching Probit Model (ESPM). We follow Cappellari and Jenkins (2004) and use a bivariate probit where the first equation describes the poverty status in period $t-1$ (basis poverty status) and the second equation describes the poverty status at $t$ conditional on the poverty status at $t-1$ (poverty transition) 4 The model writes as follows:

Basis poverty status:

$$
P\left(p_{i t-1}=1\right)=\Phi\left(\alpha^{\prime} z_{i t-1}\right)
$$

Poverty transition:

$$
P\left(p_{i t}=1 \mid p_{i t-1}\right)=\mathbf{\Phi}\left(\left[p_{i t-1} \beta_{1}^{\prime}+\left(1-p_{i t-1}\right) \beta_{2}^{\prime}\right] x_{i t}\right)
$$

where $p_{i t-1}$ and $p_{i t}$ are poverty status at $t-1$ and $t$ respectively. The $z_{i t}$ and $x_{i t}$ vectors are vectors of exogenous explanatory variables and $\Phi$ is the standard normal cumulative distribution function. The scalar $i, i=1 \ldots N$, indexes individuals and the scalar $t$ indexes time.

In terms of latent poverty propensity, equations (10) and (11) translate into equations (12) and (13):

Poverty propensity at $t-1$ :

$$
p_{i t-1}^{*}=\alpha^{\prime} z_{i t-1}+u_{i t-1}
$$

Poverty propensity at $t$ :

$$
p_{i t}^{*}=\left[p_{i t-1} \beta_{1}^{\prime}+\left(1-p_{i t-1}\right) \beta_{2}^{\prime}\right] x_{i t}+v_{i t}
$$

with

$$
\rho=\operatorname{corr}\left(u_{i t-1}, v_{i t}\right)
$$

We assume that $u_{i t-1}$ and $v_{i t}$ follow standard normal distributions. As stated in equation (14), the correlation between unobservable factors determining $p_{i t-1}^{*}$ and $p_{i t}^{*} \mid p_{i t-1}$ is called $\rho$. The estimate of $\rho$ provides a test for initial poverty status exogeneity. If $\rho$ is not significantly different from 0 , there is no so-called initial condition problem and the poverty status at $t-1$ has no impact on the probability to be poor at $t$. A positive (respectively negative) sign for $\rho$ indicates that households that were more likely to be poor at $t-1$ are

\footnotetext{
${ }^{4}$ This equation corresponds to the conditional current poverty status equation but for simplicity we refer to it as the poverty transition equation.
} 
also more (respectively less) likely to be poor at $t$ compared to households that were not poor at $t-1$.

This model is parametrized such as each element of $x_{i t}$ in the poverty transition equation may have a different impact on poverty status at $t$ depending on poverty status at $t-1$. Estimation of the model thus provides, on one hand, a poverty persistence model : $P\left(p_{i t}=\right.$ $\left.1 / p_{i t-1}=1\right)=\Phi_{\mathbf{2}}\left(\beta_{1}^{\prime} x_{i t} ; \alpha^{\prime} z_{i t-1}\right)$ and, on the other hand, a poverty entry model $P\left(p_{i t}=\right.$ $\left.1 / p_{i t-1}=0\right)=\Phi_{\mathbf{2}}\left(\beta_{2}^{\prime} x_{i t} ;-\alpha^{\prime} z_{i t-1}\right)$.

\subsubsection{Estimation}

In this model, three sets of parameters have to be estimated: first, the parameters determining initial poverty status: $\alpha=\left(\alpha_{1}, \alpha_{2}\right)$; second, the parameters determining current conditional poverty status: $\beta=\left(\beta_{1}, \beta_{2}\right)$; third, the correlation between non-observable effects affecting these processes: $\rho=\left(\rho_{1}, \rho_{2}\right)$. The 1 subscript refers to the poverty persistence model and the 2 subscript refers to the poverty entry model.

These models can be consistently estimated by a maximum likelihood estimator if the errors terms associated to latent variables of the poverty transition and the basis poverty status equation follow a bivariate normal distribution and are independent of the explanatory variables (Wooldridge, 2001). To obtain convincing estimation results, it is required that at least one variable in $z_{i t}$, the vector of variables determining initial poverty status, is not in $x_{i t}$. Otherwise, identification is off of the non-linearities in the probit models.

\subsubsection{Unobserved heterogeneity}

a) Pooled Model:

The error terms of equations (12) and (13) can be written as sums of an household specific effect plus an orthogonal white noise error as follows:

$$
\begin{gathered}
u_{i t-1}=\mu_{i}+\delta_{i t-1} \\
v_{i t}=\tau_{i}+\varsigma_{i t} .
\end{gathered}
$$

This specification allows (unobservable) time invariant households characteristics contained in $\mu_{i}$ and $\tau_{i}$ to affect both initial poverty status and poverty transition in addition to observed households characteristics.

We follow Cappellari and Jenkins' approach and pool data from pairs of consecutive years so that $\rho=\operatorname{corr}\left(u_{i t-1}, v_{i t}\right)=\operatorname{corr}\left(\mu_{i}, \tau_{i}\right)$. If $u_{i t-1}$ and $v_{i t}$ follow standard normal distributions, $\left(\beta_{1}, \rho_{1}\right)$ and $\left(\beta_{2}, \rho_{2}\right)$ can be estimated by maximizing the sample likelihood:

Poverty persistence model: 


$$
\begin{aligned}
\ln L= & \sum_{\substack{j \in S \\
p_{i t-1=1} \\
p_{i t}=1}} \ln \Phi_{2}\left(\beta_{1}^{\prime} x_{i t}, \alpha^{\prime} z_{i t-1}, \rho_{1}\right)+ \\
& \sum_{\substack{j \in S \\
p_{i t-1=1}=1 \\
p_{i t}=0}} \ln \Phi_{2}\left(-\beta^{\prime}{ }_{1} x_{i t}, \alpha^{\prime} z_{i t-1}, \rho_{1}\right)+ \\
& \sum_{\substack{j \notin S \\
p_{i t-1}=0}} \ln \Phi\left(1-\alpha^{\prime} z_{i t-1}\right)
\end{aligned}
$$

Poverty entry model:

$$
\begin{aligned}
\ln L= & \sum_{\substack{j \in S \\
p_{i-1}=0 \\
p_{i t}=1}} \ln \Phi_{2}\left(\beta^{\prime}{ }_{2} x_{i t}, 1-\alpha^{\prime} z_{i t-1}, \rho_{2}\right)+ \\
& \sum_{\substack{j \in S \\
p_{i-1}=0 \\
p_{i t}=0}} \ln \Phi_{2}\left(-\beta^{\prime}{ }_{2} x_{i t}, 1-\alpha^{\prime} z_{i t-1}, \rho_{2}\right)+ \\
& \sum_{\substack{j \notin S \\
p_{i t-1}=1}} \ln \Phi\left(\alpha^{\prime} z_{i t-1}\right)
\end{aligned}
$$

where transitions are indexed by $j, j=1, \ldots, J, \Phi_{2}($.$) is the cumulative bivariate normal$ distribution function and $\Phi($.$) is the standard cumulative normal. \mathrm{S}$ is the set of selected observations, that is individuals who are poor at $t-1$ for the poverty persistence model and individual who are not poor at $t-1$ for the poverty entry model. Standards errors are adjusted to account for the correlation over time of observations belonging to the same household. The main advantage of this model is its robustness to the violation of the strict exogeneity assumption. The pooled estimator, contrary to the traditional random effect estimator, indeed does not require making assumption on the joint distribution of $\left(p_{i 1}, \ldots, p_{i T}\right)$. Maximizing $N^{-1} \sum_{i=1}^{N} \sum_{t=1}^{T} \log \left[f\left(p_{i t} \mid x_{i t}, z_{i t-1}, \alpha, \beta, \rho\right)\right]$, with $f$ the conditional density function of $p_{i t}$ leads to consistent estimators of $(\alpha, \beta, \rho)$ (Wooldridge, 2001).

b) Chamberlain approach of household time invariant unobserved heterogeneity

To obtain consistent estimates, unobservable time invariant households characteristics contained in $\mu_{i}$, such as motivation and intelligence, are required not being correlated with explanatory variables like education level for example. This is unlikely to be true. One can relax this assumption by using the Chamberlain approach (Wooldridge, 2001; Chamberlain, 1980) and by writing $\mu_{i}$ as a function of the explanatory variables:

$$
\mu_{i}=\bar{x}_{i} \xi+a_{i}
$$


with $\bar{x}_{i}=\frac{1}{T} \sum_{i=1, \ldots, T} x_{i t}$ and $a_{i} / \bar{x}_{i} \hookrightarrow \operatorname{Normal}\left(0, \sigma_{a}^{2}\right)$.

Dividing the original parameters by $\sqrt{\operatorname{var}\left(a_{i}+e_{i t}\right)}=\sqrt{\left(1+\sigma_{a}^{2}\right)}$ leads to the following expression for the poverty transition equation:

$$
P\left(p_{i t}=1 \mid p_{i t-1}\right)=P\left(\left(p_{i t-1} \beta_{1}^{a \prime}+\left(1-p_{i t-1}\right) \beta_{2}^{a \prime}\right) x_{i t}+\bar{x}_{i} \xi^{a}+\frac{a_{i}+\varsigma_{i t}}{\sqrt{\left(1+\sigma_{a}^{2}\right)}}>0\right) .
$$

This model is a simple probit model where the error term follows a standard normal distribution. The superscript $a$ describes the original parameters divided by $\sqrt{\left(1+\sigma_{a}^{2}\right)}$. The parameters of this model $\left(\beta^{a}, \xi^{a}, \alpha^{a}, \rho^{a}\right)$ can be consistently estimated by a random effect probit estimator under the assumption of no correlation between the residual error term, $\frac{a_{i}+\varsigma_{i t}}{\sqrt{\left(1+\sigma_{a}^{2}\right)}}$, and explanatory variables. This is likely to be the case since the time-invariant part of explanatory variables is removed from the error term using the Chamberlain approach. Standards errors have to be adjusted for correlation over time within households.

\subsubsection{Poverty transitions probabilities}

The poverty transition probabilities are easily derived from the model. The poverty persistence probability, i.e, the probability of being poor at $t$, conditional on being poor at $t-1$, is given by:

$$
s_{i t}=P\left(p_{i t}=1 \mid p_{i t-1}=1\right)=\frac{\boldsymbol{\Phi}_{\mathbf{2}}\left(\beta_{1}^{\prime} x_{i t}, \alpha^{\prime} z_{i t} ; \rho_{1}\right)}{\mathbf{\Phi}\left(\alpha^{\prime} z_{i t}\right)}
$$

The poverty entry probability, i.e., the probability of being poor at $t$, conditional on being non-poor at $t-1$, is given by:

$$
e_{i t}=P\left(p_{i t}=1 \mid p_{i t-1}=0\right)=\frac{\boldsymbol{\Phi}_{\mathbf{2}}\left(\beta_{2}^{\prime} x_{i t},-\alpha^{\prime} z_{i t} ;-\rho_{2}\right)}{\mathbf{\Phi}\left(-\alpha^{\prime} z_{i t}\right)}
$$

\subsection{5 (Average) Partial effects}

The $\beta$ parameters are interesting to study the significance and the direction of the impact of explanatory variables. However, the quantities of interest are the partial effects of explanatory variables on the probability to be poor. Since our model is non-linear, partial effects of explanatory variables are not constant along the distribution of the explanatory variables. We choose to present, on one hand, average partial effect on the whole sample and, on the other hand, partial effect of explanatory variables on different types of households.

The average partial effect of a continuous variable $x_{i t}^{k}$ writes as follows: 
If one is poor at $t-1$,

$$
E_{i}\left[\frac{d p_{i t}}{d x_{i t}^{k}}\right]=\beta_{1}^{k} E_{i}\left[\frac{\mathbf{\Phi}_{\mathbf{2}}\left(\beta_{1}^{\prime} x_{i t}, \alpha^{\prime} z_{i t} ; \rho_{1}\right)}{\mathbf{\Phi}\left(\alpha^{\prime} z_{i t}\right)}\right]
$$

with $\beta_{1}=\left\{\beta_{1}^{k}\right\}, k \in[1, K] . K$ is the number of explanatory variables.

If one is non-poor at $t-1$,

$$
E_{i}\left[\frac{d p_{i t}}{d x_{i t}^{k}}\right]=\beta_{2}^{k} E_{i}\left[\frac{\boldsymbol{\Phi}_{\mathbf{2}}\left(\beta_{2}^{\prime} x_{i t},-\alpha^{\prime} z_{i t} ;-\rho_{2}\right)}{\mathbf{\Phi}\left(-\alpha^{\prime} z_{i t}\right)}\right]
$$

with $\beta_{2}=\left\{\beta_{2}^{k}\right\}, k \in[1, K]$.

These quantities are consistently estimated by:

$$
E_{i}\left[\frac{d p_{i t}}{d x_{i t}^{k}}\right]=\beta_{1}^{k} \frac{1}{N} \sum_{i}\left[\frac{\mathbf{\Phi}_{\mathbf{2}}\left(\beta_{1}^{\prime} x_{i t}, \alpha^{\prime} z_{i t} ; \rho_{1}\right)}{\mathbf{\Phi}\left(\alpha^{\prime} z_{i t}\right)}\right]
$$

and,

$$
E_{i}\left[\frac{d p_{i t}}{d x_{i t}^{k}}\right]=\beta_{2}^{k} \frac{1}{N} \sum_{i}\left[\frac{\boldsymbol{\Phi}_{\mathbf{2}}\left(\beta_{2}^{\prime} x_{i t},-\alpha^{\prime} z_{i t} ;-\rho_{2}\right)}{\mathbf{\Phi}\left(-\alpha^{\prime} z_{i t}\right)}\right]
$$

For a dichotomous variable $x_{i t}^{k}$, we compute the change in the probability transition when the dichotomous variable varies from zero to one. If one is poor at $t-1$, the average partial effect of $x_{i t}^{k}$ is consistently estimated by:

$$
\begin{aligned}
E_{i}\left[\frac{d p_{i t}}{d x_{i t}^{k}}\right]= & \frac{1}{N}\left(\sum_{i}\left[\frac{\mathbf{\Phi}_{\mathbf{2}}\left(\beta_{1}^{1} x_{i t}^{1}+\ldots+\beta_{\mathbf{1}}^{\mathbf{k}} \cdot \mathbf{1}+\ldots+\beta_{1}^{K} x_{i t}^{K}, \alpha^{\prime} z_{i t} ; \rho_{1}\right)}{\mathbf{\Phi}\left(\alpha^{\prime} z_{i t}\right)}\right]-\right. \\
& \sum_{i}\left[\frac{\mathbf{\Phi}_{\mathbf{2}}\left(\beta_{1}^{1} x_{i t}^{1}+\ldots+\beta_{\mathbf{1}}^{\mathbf{k}} \mathbf{0}+\ldots+\beta_{1}^{K} x_{i t}^{K}, \alpha^{\prime} z_{i t} ; \rho_{1}\right)}{\mathbf{\Phi}\left(\alpha^{\prime} z_{i t}\right)}\right)
\end{aligned}
$$

If one is non-poor at $t-1$, the average partial effect of $x_{i t}^{k}$ is consistently estimated by:

$$
\begin{aligned}
E_{i}\left[\frac{d p_{i t}}{d x_{i t}^{k}}\right]= & \frac{1}{N}\left(\sum_{i}\left[\frac{\mathbf{\Phi}_{\mathbf{2}}\left(\beta_{2}^{1} x_{i t}^{1}+\ldots+\beta_{\mathbf{2}}^{\mathbf{k}} \cdot \mathbf{1}+\ldots+\beta_{2}^{K} x_{i t}^{K},-\alpha^{\prime} z_{i t} ;-\rho_{2}\right)}{\mathbf{\Phi}\left(-\alpha^{\prime} z_{i t}\right)}\right]-\right. \\
& \sum_{i}\left[\frac{\boldsymbol{\Phi}_{\mathbf{2}}\left(\beta_{2}^{1} x_{i t}^{1}+\ldots+\beta_{\mathbf{2}}^{\mathbf{k}} \cdot \mathbf{0}+\ldots+\beta_{2}^{K} x_{i t}^{K},-\alpha^{\prime} z_{i t} ;-\rho_{2}\right)}{\mathbf{\Phi}\left(\alpha^{\prime} z_{i t}\right)}\right)
\end{aligned}
$$

We can also compute partial effects for particular households. For a reference households with characteristics $x_{i t}=x_{i t}^{\circ}$, the partial effect of a continuous variable $x_{i t}^{k}$ on the probability to be poor at $t$ writes:

$$
\left[\frac{d p_{i t}}{d x_{i t}^{k}}\right]_{x_{i t}=x_{i t}}=\left[\frac{d P\left(p_{i t}=1 \mid p_{i t-1}\right)}{d x_{i t}^{k}}\right]_{x_{i t}=x_{i t}^{\circ}}
$$


If the household is poor at $t-1$, we have:

$$
\left[\frac{d p_{i t}}{d x_{i t}^{k}}\right]_{x_{i t}=x_{i t}^{\circ}}=\beta_{1} \frac{\boldsymbol{\Phi}_{2}\left(\beta_{1}^{\prime} x_{i t}^{\circ}, \alpha^{\prime} z_{i t}^{\circ} ; \rho_{1}\right)}{\boldsymbol{\Phi}\left(\alpha^{\prime} z_{i t}^{\circ}\right)}
$$

If the household is non-poor at $t-1$, we have :

$$
\left[\frac{d p_{i t}}{d x_{i t}^{k}}\right]_{x_{i t}=x_{i t}^{\circ}}=\beta_{2} \frac{\boldsymbol{\Phi}_{\mathbf{2}}\left(\beta_{2}^{\prime} x_{i t}^{\circ},-\alpha^{\prime} z_{i t}^{\circ} ;-\rho_{2}\right)}{\mathbf{\Phi}\left(-\alpha^{\prime} z_{i t}^{\circ}\right)}
$$

It is worth noting that relative partial effects of two variables are independent of the values of the explanatory variables. The relative partial effect of $x_{j}$ and $x_{l}$ writes:

$$
\frac{\left(\frac{\delta p_{1 i t}}{\delta x_{j}}\right)}{\left(\frac{\delta p_{1 i t}}{\delta x_{l}}\right)}=\frac{\hat{\beta}_{j} E[\Phi(.)]}{\hat{\beta}_{l} E[\Phi(.)]}=\frac{\hat{\beta}_{j}}{\hat{\beta}_{l}}
$$

Partial effects of two variables can thus easily be compared.

\subsubsection{State dependence}

We follow Cappellari and Jenkins (2004) by distinguishing aggregate state dependence (ASD) and genuine state dependence (GSD). ASD is the difference between the probability to be poor at $t$ conditional on being poor at $t-1$ and the probability to be poor at $t$ conditional on not being poor at $t-1$, taking no account of individual heterogeneity. ASD can be empirically calculated as the difference between the poverty persistence and the poverty entry rate :

$$
A S D=\frac{\sum_{j \in\left\{p_{j t-1}=1\right\}} P\left(p_{j t}=1 \mid p_{j t-1}=1\right)}{\sum_{j} p_{j t-1}}-
$$

GSD measure the increase in the probability of being poor at $t$ due to poverty at $\mathrm{t}-1$, controlling for individual heterogeneity. Our model is parametrized such that each element of $x_{i t}$ in the poverty transition equation may have a different impact on poverty status at $t$ depending on poverty status at $t-1$. A simple test for state dependence is obtained by comparing the estimates of the parameters associated to explanatory variables, that is $\beta_{2}=\beta_{1}$. The null hypothesis of a test of GSD can be formulated as follows: $H o: \beta_{2}=\beta_{1}$. In other words, state dependence translates in the difference between $\beta_{2}$ and $\beta_{1}$ for each 
explanatory variable. An aggregate measure of state dependence is the increase in the probability of being poor at $t$ due to poverty at $t-1$. It can be calculated as the average on the whole population of the increase in the probability of being poor at $t$ due to poverty at $t-1$. Empirically, it translates as follows

$$
\begin{aligned}
G S D & =\frac{1}{N} \sum_{i=1 \ldots N}\left[\widehat{P}\left(p_{i t}=1 \mid p_{i t-1}=1\right)-\widehat{P}\left(p_{i t}=1 \mid p_{i t-1}=0\right)\right] \\
& =\frac{1}{N} \sum_{i=1 \ldots N}\left[\frac{\boldsymbol{\Phi}_{\mathbf{2}}\left(\widehat{\beta}_{1}^{\prime} x_{i t}, \widehat{\alpha}^{\prime} z_{i t} ; \rho_{1}\right)}{\mathbf{\Phi}\left(\widehat{\alpha}^{\prime} z_{i t}\right)}-\frac{\boldsymbol{\Phi}_{\mathbf{2}}\left(\widehat{\beta}_{2}^{\prime} x_{i t},-\widehat{\alpha}^{\prime} z_{i t} ;-\rho_{2}\right)}{\mathbf{\Phi}\left(-\widehat{\alpha}^{\prime} z_{i t}\right)}\right]
\end{aligned}
$$

The calculation of household specific probability ensures that time invariant household heterogeneity is controlled for.

\subsubsection{Limitations}

The pooled estimator does not allow to estimate unobserved heterogeneity. Moreover, the impact of poverty in this model is measured only through the interaction with observed explanatory variables. All others transmission channels are ignored.

\section{Data}

\subsection{Data Source}

The database is assembled from annual surveys conducted by the Réseau des Observatoires Ruraux (ROR) in several rural areas of Madagascar. The ROR is a joint project of the Malagasy National Statistical Institute (INSTAT) and the Institut de Recherche pour le Développement (IRD) based in Paris. The survey began in 1995 in four areas and was extended to several other rural areas in 1999. Among the twenty four surveyed areas, one has been surveyed for eleven years, one for ten years, four for eight years, three for seven years, four for six years, two for four years, four for three years and five for two years over the period 1995-2006. Areas are chosen to illustrate different facets of the Malagasy rural economy. The areas strongly differ from each other in terms of agronomic and climatic conditions, population density and remoteness. Within each selected area, five hundred households are randomly chosen from an exhaustive list. The household sample is not statistically representative of the country but is representative within each area. The same households are interviewed each year so that a panel can be constructed. Households that have moved or are unwilling to be interviewed are substituted by new households with similar characteristics from the same area. Annual surveys collect data on household housing, socio-demographics, education, income sources, agricultural production (landholding, crops, husbandry, farm technology, inputs, and stocks), expenditures in food as well as non-food items and agro-climatic shocks. A common methodology of sampling, survey methodology, training of pollsters and supervisors and data preparation is used in 
the surveyed areas so that comparisons among areas are meaningful. This feature makes this database unique and very useful to follow poverty and living conditions for a long period and in a wide range of agro-geographic conditions, at least compared with what is usually available in developing countries (Droy et al., 2001).

\subsection{Poverty Dynamics}

We use consumption rather than income to measure living standards since data on consumption are usually considered as a good indicator of living standards in developing countries (Ravallion, 1992; Deaton and Grosh., 2000). In developing countries, consumption is smoother whereas income is received irregularly. When the reference period used to collect data on consumption and income is short, information on consumption is better able to describe current living standards than income. Regarding measurement errors, both consumption and income are difficult to measure. However, consumption patterns are less complex in poor countries than in rich countries and are more easily caught in surveys. Moreover, surveys often face great difficulties dealing with self-employment, informal economic activities, and widespread reluctance to disclose information on income, three widespread phenomena in developing countries. Our consumption aggregate is calculated as the sum of food and non-food consumption. The measure of food consumption includes cash expenditures on food and the imputed value of home consumption 5 The measure of non-food consumption includes expenditures on clothing, health, housing, education, recreation, transportation and rituals. Durables are excluded from this aggregate. Per capita consumption is obtained by dividing household consumption by household size in adult equivalent according to the oxford equivalence scale 6

A poverty line is necessary to identify poor households. We use the absolute poverty line of 998600 Malagasy Francs (Fmg) in 2001 defined by the INSTAT according to international standards (INSTAT, 2002). This poverty line corresponds to value of indispensable non-food elements and a food ration of $2133 \mathrm{kcal}$ per day. This value is deflated by the national consumer price index to get the value of the poverty line for the other years. Obtained poverty rates are very high. Around 70 percent of the rural households are poor in our sample on the whole observation period. This is consistent with the poverty rates obtained by national surveys run on the same period (INSTAT, 1999, 2003, 2004, 2006, 2011).

Average transitions probabilities for our sample are described in Table 1. As expected, poverty is highly persistent. The poverty persistence rate is 0.82 on average. Transitory poverty is also important since the poverty entry rate is 0.44 and the poverty exit rate

\footnotetext{
${ }^{5}$ Annual mean of market prices is used when available. Otherwise, producer prices retrieved from declared sales in the survey questionnaire are used.

${ }^{6}$ According to this equivalence scale, the weights are the following: children aged less than three: .35, from three to five years old: .5, from five to ten years old: .6, from ten to seventeen years old:.7, women above twenty-one years old: .85, Men above seventeen years old and women between seventeen and twenty-one years old: 1.
} 


\begin{tabular}{rrr}
\hline & \multicolumn{2}{c}{ Poverty status, year t } \\
\cline { 2 - 3 } Poverty status, year t-1 & Not poor & Poor \\
\hline (a) Complete Panel: & Sample size=43626 observations, 16126 households \\
Not poor & 55,67 & 44,33 \\
Poor & 17,84 & 82,16 \\
All & 27,46 & 72,54 \\
& & \\
\hline (b) Balanced Panel: & Sample size=18545 observations, 6139 households \\
Not poor & 56,51 & 43,49 \\
Poor & 18,04 & 81,96 \\
All & 27,81 & 72,19 \\
\hline The poverty line is evaluated at 988600 Fmg in 2001 (INSTAT, 2002) and is deflated by \\
the national IPC for the other years.
\end{tabular}

Table 1: Poverty transition matrix, ROR surveys 1999-2006, pooled data

is a little less than 0.2 We can calculate aggregate state dependence as proposed by Cappellari and Jenkins (2004) and described by equation (31). ASD equals .38 meaning that the probability to be poor at $t$ is 38 percentage points higher when poor at $t-1$. rather than non-poor at $t-1$.

Transition rates and ASD vary from one area to the other. Figure 1 represents the poverty persistence and poverty entry rates by area. Four groups of areas can be arbitrarily distinguished. The first group includes highly vulnerable to poverty areas in the upper right corner of Figure 1. The two areas in this group have poverty persistence rates above 0.9 and poverty entry rates about 0.8 . These areas are of course among the poorest areas of Madagascar. Poverty headcount is above 0.9. In the most vulnerable area, Fianarantsoa, poverty is related to remoteness (Razafindravonona et al., 2001). In the second most vulnerable area, Ambovombe, situated in the South of Madagascar, the climate is often claimed to be responsible for high poverty rates. The area is subject to a dry tropical climate with a rainy season not exceeding three months. Crops are cyclically affected by climatic events like irregular distribution of rainfall or droughts. Famines and food shortages are frequent and food vulnerability is widespread (Bidou and Droy, 2009). The second group is composed of areas that are vulnerable to poverty. This group is formed by nine or ten areas where the probability of remaining poor is greater than 0.8 and where the probability of entering poverty is greater than 0.5 . Several of these areas are located in the South of Madagascar and thus face a dry climate, regular droughts but also flooding during the brief rainy season whereas the others are located on the East Coast of Madagascar and are thus regularly hit by typhoons and extreme climatic events. In the center of Figure 1, the third group is characterized by low mobility. The probability of remaining poor is greater than 0.65 , and the probability of remaining non-poor is greater than 0.55 . We namely find in this group the areas where cash crops, namely coffee and vanilla, are 


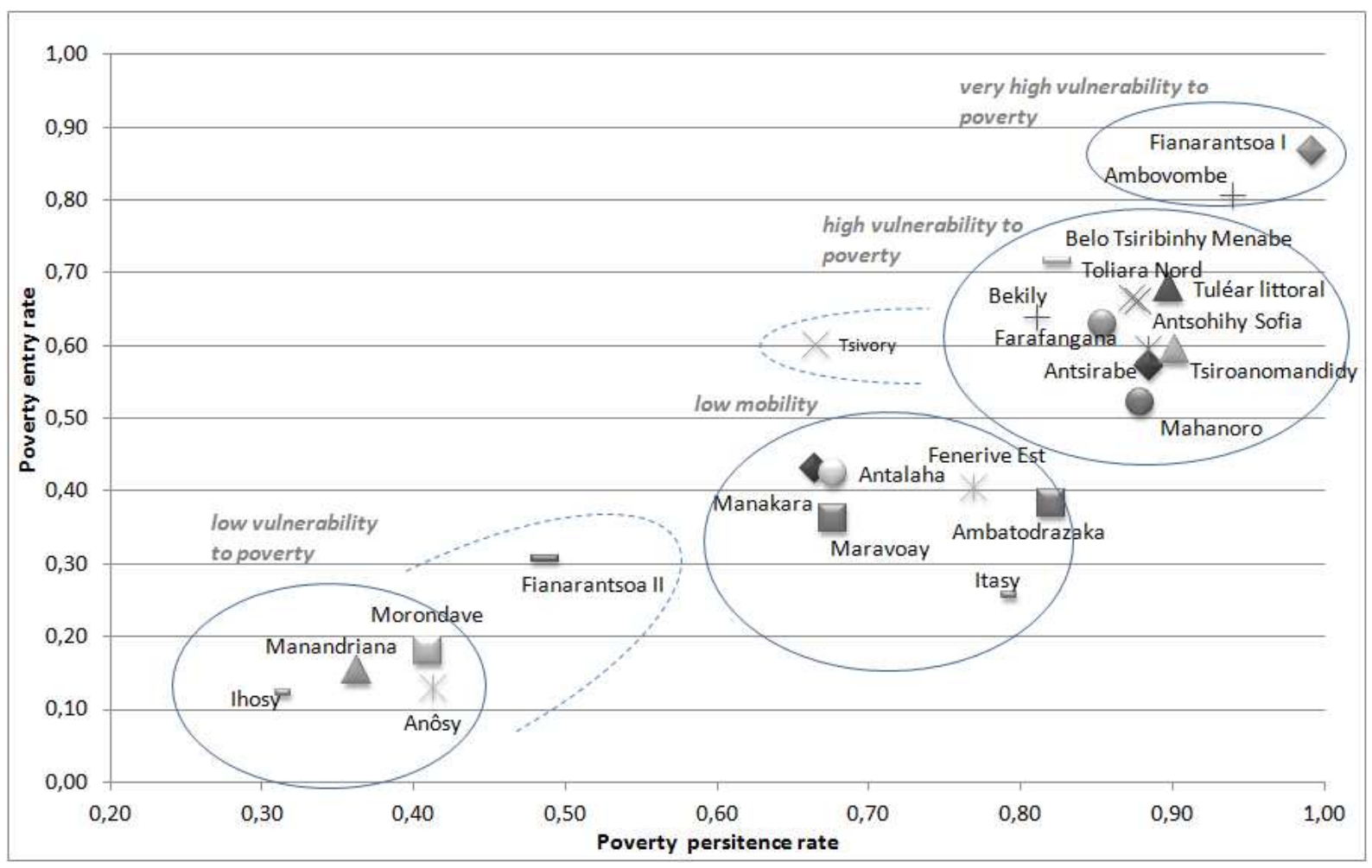

Figure 1: Poverty entry and persistence rates, by area, ROR surveys 1996-2006, pooled data.

grown. The four and latest group shows more favorable prospects. The upward mobility is relatively high. The probability to leave poverty is higher than 0.5. And the probability to remain non-poor is above 0.7 .

The further the points from the diagonal of Figure 1, the greater the ASD. On the opposite, the closer the points from the diagonal on Figure 1, the lower the ASD. It may be worth noting that there is no evident link between poverty level and ASD. In other words, we can observe high level of poverty and high persistence, high level of poverty and low persistence (implying high transient poverty), low level of poverty and low persistency, low level of poverty and high persistency. The level of ASD is explained by local specific factors. For instance, the lowest ASD is found in Tsivory, an very poor area situated in the South East of Madagascar. Following the 1991 food shortage, the Malagasy national government and the International Fund for Agricultural Development launched an rural development project. It has apparently reduced the impact of past on future poverty compared to other Malagasy rural areas. The project namely contains a rural finance section that may help households to deal with adverse shocks. On the opposite, Itasy, the 
area with the highest ASD has a below average poverty rate. The distribution of assets and income in this area is very unequal because of a high land pressure. Poverty traps and polarization are likely to occur in this area.

\subsection{Explanatory Variables}

The set of explanatory variables is similar to that commonly found in the literature on poverty dynamics. Our econometric models impose that the explanatory variables be predetermined when pooled estimators are used and strictly exogenous when random effect estimators are used.

The set of socio-demographic explanatory variables includes the age and gender of the household head as well as variables depicting the family structure and the number of household members by age. We control separately for children, adults and elders. Adults are assumed to be working and are more likely to decrease poverty propensity whereas children and elders are so-called dependents and are more likely to increase poverty propensity by putting pressure on households' resources.

The set of economic explanatory variables includes the size of land owned by the households, livestock and the share of each income-generating activity in total income. The current value of assets levels is likely to be correlated with current poverty transitions. Households indeed willingly resort to livestock selling to cope with negative shocks. We thus introduce lagged values of these variables. Land is seldom used to smooth consumption so that the area owned is practically time-invariant. We, however, also use the lagged value of this variable.

We also want to control for income and consumption shocks. Available information in the survey contains household self-declared intensity of shocks on rice, maize and tuber fields. We also consider change in household head gender, household size and family structure as consumption shocks. Systemic shocks (price and rainfall shocks for example) are controlled for through the inclusion of time and location dummies. 


\begin{tabular}{|c|c|c|c|c|c|c|c|c|}
\hline \multirow[b]{2}{*}{ Proportion in the sample } & \multicolumn{2}{|c|}{ stay poor } & \multicolumn{2}{|c|}{ enter poverty } & \multicolumn{2}{|c|}{ exit poverty } & \multicolumn{2}{|c|}{ stay non-poor } \\
\hline & 0,6128 & 0.6114 & 0,1127 & 0.1105 & 0,1331 & 0.1345 & 0,1415 & 0.1435 \\
\hline \multicolumn{9}{|l|}{ Socio-demographic characteristics } \\
\hline Household size & 6,21 & 6,06 & 5,3 & 5,28 & 5,21 & 5,35 & 4,61 & 4,83 \\
\hline Dependancy ratio & 1,58 & 1,55 & 1,37 & 1,36 & 1,33 & 1,31 & 1,12 & 1,16 \\
\hline Female headed households & 0,19 & 0,19 & 0,17 & 0,17 & 0,17 & 0,17 & 0,16 & 0,17 \\
\hline Age of household head & 46,16 & 46,05 & 44,89 & 44,81 & 44,99 & 45,07 & 44,14 & 44,23 \\
\hline Single & 0,01 & 0,02 & 0,02 & 0,03 & 0,06 & 0,06 & 0,08 & 0,07 \\
\hline Couples & 0,02 & 0,02 & 0,04 & 0,04 & 0,05 & 0,05 & 0,07 & 0,06 \\
\hline Couples with children & 0,51 & 0,50 & 0,48 & 0,47 & 0,47 & 0,46 & 0,45 & 0,45 \\
\hline Monoparental family & 0,09 & 0,09 & 0,07 & 0,07 & 0,10 & 0,09 & 0,07 & 0,07 \\
\hline Extended family & 0,38 & 0,37 & 0,38 & 0,38 & 0,33 & 0,34 & 0,33 & 0,34 \\
\hline No education & 0,34 & 0,32 & 0,26 & 0,26 & 0,25 & 0,26 & 0,16 & 0,18 \\
\hline Education of household head & 2,77 & 2,88 & 3,54 & 3,55 & 3,53 & 3,52 & 4,58 & 4,39 \\
\hline Education of household head's wife & 1,88 & 1,97 & 2,41 & 2,39 & 2,41 & 2,4 & 3,14 & 2,98 \\
\hline \multicolumn{9}{|l|}{ Economic characteristics } \\
\hline Owner of livestock & 0,44 & 0,68 & 0,51 & 0,70 & 0,53 & 0,72 & 0,56 & 0,74 \\
\hline Catlle owned (among cattle owner) & 3,61 & 3,61 & 5,31 & 5,40 & 4,93 & 5,20 & 6,05 & 6,45 \\
\hline Porks owned (among porks owner) & 0,94 & 0,93 & 1,19 & 1,25 & 1,15 & 1,26 & 1,55 & 1,56 \\
\hline Goats owned (among goats owner) & 5,88 & 5,62 & 7,89 & 8,50 & 8,09 & 8,95 & 7,63 & 9,10 \\
\hline Poultry (among poultry owner) & 8,17 & 8,21 & 10,29 & 10,22 & 10,44 & 10,64 & 12,97 & 13,51 \\
\hline Land owners & 0,61 & 0,61 & 0,69 & 0,68 & 0,72 & 0,72 & 0,76 & 0,77 \\
\hline Surface owned & 65,08 & 59 & 90,60 & 75 & 91,03 & 87 & 126,90 & 114 \\
\hline Rice producers & 0,68 & 0,67 & 0,77 & 0,76 & 0,79 & 0,79 & 0,84 & 0,84 \\
\hline Maize producer & 0,46 & 0,45 & 0,44 & 0,42 & 0,48 & 0,48 & 0,47 & 0,42 \\
\hline Cassava Producer & 0,61 & 0,65 & 0,57 & 0,58 & 0,61 & 0,61 & 0,55 & 0,59 \\
\hline Cash crops producer (vanillia, coffee) & 0,02 & 0,01 & 0,04 & 0,06 & 0,06 & 0,07 & 0,10 & 0,07 \\
\hline Agricultural wage worker & 0,42 & 0,39 & 0,34 & 0,31 & 0,30 & 0,31 & 0,22 & 0,26 \\
\hline Do non agricultural activities & 0,83 & 0,80 & 0,76 & 0,74 & 0,76 & 0,76 & 0,70 & 0,73 \\
\hline Share of rice in total income (TI) & 0,25 & 0,27 & 0,32 & 0,31 & 0,32 & 0,31 & 0,34 & 0,35 \\
\hline Share of other crops in (TI) & 0,28 & 0,27 & 0,26 & 0,26 & 0,25 & 0,27 & 0,22 & 0,23 \\
\hline Share of animal products in (TI) & 0,05 & 0,06 & 0,06 & 0,07 & 0,05 & 0,06 & 0,05 & 0,05 \\
\hline Share of agricultural wage work in (TI) & 0,10 & 0,09 & 0,06 & 0,06 & 0,07 & 0,07 & 0,04 & 0,04 \\
\hline Share of non agricultural activities in (TI) & 0,26 & 0,27 & 0,24 & 0,26 & 0,24 & 0,25 & 0,27 & 0,3 \\
\hline Share of cash crops in (TI) & 0,00 & 0,002 & 0,01 & 0,004 & 0,01 & 0,003 & 0,03 & 0,002 \\
\hline \multicolumn{9}{|l|}{ Shocks } \\
\hline Households hit by damages at least on one crop & 0,75 & 0,77 & 0,74 & 0,77 & 0,72 & 0,69 & 0,71 & 0,66 \\
\hline
\end{tabular}




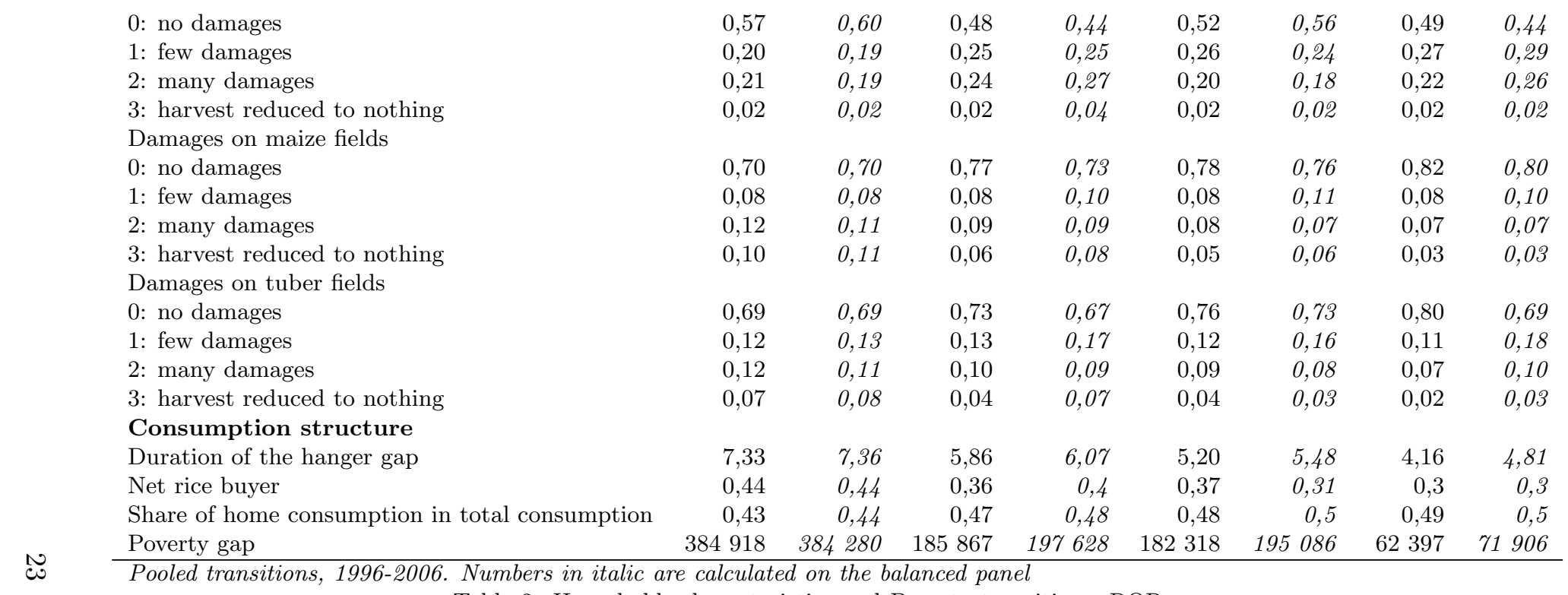

Table 2: Households characteristics and Poverty transitions, ROR sur-

veys 1996-2006 
Descriptive statistics on household characteristics associated with each poverty transitions are summarized in Table $2^{7}$

Differences in household characteristics are clearly associated with differences in transition probabilities. Chronically poor households have larger size and dependency ratio. On average, the chronic poor households count 6.2 household members and 1.58 dependents for one active whereas the transient poor count 5.2 household members and 1.33 dependents for one active and the non-poor count 4.61 household members and 1.12 dependents for one active. Single individuals and couples without children are better protected against poverty whereas couples with children and extended families are more frequently poor. Household education is also strongly correlated with lower probability to be poor. A larger proportion of uneducated households is found among the chronic poor $(34 \%)$ than among the transient poor $(\approx 25 \%)$ and the non-poor $(16 \%)$.

Asset ownership also appear to protect household from persistent and transitory poverty. Asset ownership increases both in frequency and quantity from the chronic poor to the transient poor and the non-poor. The pattern of income generating activities also differ between the different poverty transition groups. The proportion of rice and cash crop producers is larger among the non-poor whereas the proportion of tuber producers, agricultural wage workers and households carrying out non-agricultural activities are is larger among the chronic poor.

Moreover, a larger proportion of the chronic and transient poor have suffered damages on tuber and maize fields compared to non-poor households. On the contrary, the proportion of households suffering damages on their rice fields does not differ between groups.

Regarding the consumption side, the chronic poor have longer hanger gap 8 The chronic poor are more often net buyers of rice. Their share of self-consumption in total consumption is lower. Finally, the chronic poor experience more intense poverty spells than the transient poor.

What part of these differences is due to past poverty? The degree of genuine state dependency will be measured by our econometric models.

To obtain convincing estimation results in the ESPM, at least one variable in $z_{i t}$, the vector of variables determining initial poverty status, is required not to be also in $x_{i t}$, the vector of variables determining poverty transition. Otherwise, identification is off of the nonlinearities in the probit models. Our identifying variable is the occurrence of crop shocks at $t-2$. It is indeed shown in Thomas (2011, chap.3) that the consequences of idiosyncratic shocks on consumption are insured within one year. Crop shocks at $t-2$ impact only contemporaneous household consumption growth, i.e., between $t-2$ and $t-1$, but not consumption at year $t$. Idiosyncratic shocks at $t-2$ thus affect poverty status at $t-1$ but not the poverty status at $t$. The $x_{i t}$ vector contains an indicator variable equals

\footnotetext{
${ }^{7}$ Since transitions are pooled, households characteristics in each column are weighted by the frequency of the corresponding transitions

${ }^{8}$ The hanger gap is the time between harvests when food supplies are running low and market prices of staple foods are very high.
} 
to one if the household has suffered crop damages on its crop at $t-2$, variables describing changes in household size and head gender between $t-2$ and $t-1$.

\subsection{Sample attrition}

Attrition is an important phenomenon in our sample. Ten to forty percent of the households drop out of the survey each year. The highest attrition rates correspond to exogenous change in the survey design so that no bias is to be expected because of sample modifications. In particular, from 2003 to 2006, several survey areas have been modified. Attrition does not seem to be related neither to differences in poverty transitions nor to significant differences in household characteristics. Poverty persistence and poverty entry rates calculated in the balanced sample are not significantly different from the ones calculated in the full sample (see Table 1). Averages of household characteristics by poverty transition are also remarkably similar for the whole sample and the balanced sample (see Table 21). For all these reasons, sample attrition does not seem to be such an issue and is ignored in all the subsequent analyses presented in this chapter. A rigorous statistical analysis should be conduced to confirm this assumption. This is left for further research.

\section{Results}

Since household and environment characteristics are included both in level $\left(x_{i t}\right)$ and in average $\left(\bar{x}_{i}\right)$, it is worth explaining how the estimation results should be interpreted. The parameters associated to the variables in level can be interpreted as usual, that is as the (average) partial effects of each explanatory variable, or as the change in the dependant variable due to a change in one explanatory variable holding other explanatory factors fixed. The parameters $\xi$ associated to mean values of the explanatory variables $\left(\bar{x}_{i}\right)$ have to be interpreted as the impact of household's permanent characteristics. In other words, $\xi$ measures the impact on poverty risk of being of a given type of household, for example being a large family, being old, growing cash crops, etc .

\subsection{State Dependence}

Both ESPM and REDP models clearly indicate state dependence implying that past poverty has a true causal effect on future poverty.

The results of the estimation of the random effect dynamic probit model are presented in Table 3. Past poverty clearly increases the poverty risk. When no other explanatory variables than past poverty are introduced in the model, poverty risk increases by 0.73 percentage point when the household is poor in the preceding period. This percentage could be called the "raw state dependency" analogously to the ASD in the ESPM specification. When controlling for household characteristics, the estimate of $\theta$, the parameter associated to past poverty is still sizeable. Being poor in the preceding period still increases the 
poverty risk by 0.25 percentage point on average in our sample. It suggests that even after controlling for differences in observed and unobserved characteristics, past poverty experience is correlated with higher future poverty.

\begin{tabular}{|c|c|c|c|c|c|}
\hline Dependent variable & & & $P($ pit $=1)$ & & \\
\hline Estimation Method & & Random Effect Dy & namic Probit & & Pooled probit \\
\hline Past poverty & & & & & \\
\hline Poor at t-1 & $0.739 * * *$ & $0.275^{* * *}$ & $0.2968^{* * *}$ & 0.0501 & $0.454^{* * *}$ \\
\hline Poverty gap at $\mathrm{t}-1$ & & $0.175^{* * *}$ & & $0.0954^{* * *}$ & \\
\hline Initial conditions & & & & & \\
\hline Initially poor & $0.413^{* * *}$ & $0.0821^{* *}$ & $0.3578 * * *$ & & $0.239 * * *$ \\
\hline Initial poverty gap & & $0.0390^{* * *}$ & & $0,0753^{* * *}$ & \\
\hline Initial squared poverty gap & & & & & \\
\hline & no other & explanatory variables & $\begin{array}{l}\text { includes ho } \\
\text { characteris }\end{array}$ & $\begin{array}{l}\text { useholds and } \\
\text { ics as explan }\end{array}$ & $\begin{array}{l}\text { nvironnement } \\
\text { tory variables }\end{array}$ \\
\hline Number of observations & 43626 & 43626 & 38967 & 38967 & 38967 \\
\hline Numbers oh households & 16126 & 16126 & 15453 & 15453 & \\
\hline Log likelihood & -22697.6 & -21774.2 & -15584.323 & -15321.918 & -15344.4 \\
\hline
\end{tabular}

Table 3: State dependence, Results of Random Effect Dyanmic Probit

Model Estimation, ROR suveys, 1999-2006

It may worth noting that the APE of past poverty status in the pooled model is almost twice the APE of the random effect model. Failing to take into account the household unobserved heterogeneity thus leads to overestimating state dependency. However, unobserved household heterogeneity contains information on household past poverty in addition to household unobserved characteristics. Introducing past poverty gap in addition to past poverty status in our specification leads to a smaller overestimation of state dependency with the pooled model compared to the RE model (see Table 9 in Appendix). 


\begin{tabular}{|c|c|c|c|c|c|c|}
\hline & \multicolumn{2}{|c|}{$\begin{array}{l}\text { Pooled model } \\
\text { with selection }\end{array}$} & \multicolumn{2}{|c|}{$\begin{array}{c}\text { Pooled model+ } \\
\text { Chamberlain approach } \\
\text { with selection }\end{array}$} & \multicolumn{2}{|c|}{$\begin{array}{c}\text { RE probit } \\
\text { without selection }\end{array}$} \\
\hline & Poor a t-1 & Non poor a t-1 & Poor a t-1 & Non poor a t-1 & Poor a t-1 & Non poor a $t-1$ \\
\hline \multicolumn{7}{|l|}{ Main equation } \\
\hline \multicolumn{7}{|l|}{ Time-varying covariates } \\
\hline \multicolumn{7}{|c|}{ Socio-demographic characteristics } \\
\hline Hhd head gender & $0.0855^{*}$ & 0.0558 & 0.0332 & $0.314^{* *}$ & 0.0519 & $0.281^{*}$ \\
\hline Hhd head age & 0.000822 & $-0.00408^{*}$ & & & & \\
\hline Head education & $-0.0537 * * *$ & $-0.0485^{* * *}$ & & & & \\
\hline Spouse education & $-0.0378 * * *$ & $-0.0489^{* * *}$ & & & & \\
\hline Children under 20 & $0.159^{* * *}$ & $0.139^{* * *}$ & $0.132^{* * *}$ & $0.136^{* * *}$ & $0.150 * * *$ & $0.160^{* * *}$ \\
\hline Adults aged 20 to 64 & $0.158^{* * *}$ & $0.205^{* * *}$ & $0.244^{* * *}$ & $0.270^{* * *}$ & $0.274^{* * *}$ & $0.264^{* * *}$ \\
\hline Adults aged 60 and more & $0.265^{* * *}$ & $0.266^{* * *}$ & $0.326^{* * *}$ & $0.248^{* *}$ & $0.317^{* * *}$ & $0.272^{* * *}$ \\
\hline Change in family structure & & & $-0.123^{* * *}$ & 0.0793 & $-0.112^{* * *}$ & 0.0521 \\
\hline \multicolumn{7}{|l|}{ Shocks } \\
\hline Shock intensity on rice fields & -0.00488 & -0.00134 & 0.0119 & 0.0403 & $0.0474^{* *}$ & $0.0818^{* * *}$ \\
\hline Shock intensity on maize fields & $0.144^{* * *}$ & $0.0658^{*}$ & 0.0288 & 0.00133 & 0.0316 & 0.0149 \\
\hline Shock intensity on tuber fields & $0.0802^{* * *}$ & $0.116^{* * *}$ & -0.0105 & 0.0399 & $-0.0389 *$ & 0.0241 \\
\hline \multicolumn{7}{|c|}{ Intertemporal averages and values at $t-1$} \\
\hline \multicolumn{7}{|c|}{ Socio-demographic characteristics } \\
\hline Age (ia) & & & $0.00384^{* *}$ & -0.00271 & $0.00468^{* * *}$ & 0.000645 \\
\hline Head gender (ia) & & & 0.0663 & $-0.297^{*}$ & 0.110 & $-0.257^{*}$ \\
\hline Head education (ia) & & & $-0.0429 * * *$ & $-0.0491^{* * *}$ & $-0.0491^{* * *}$ & $-0.0517^{* * *}$ \\
\hline Spouse education (ia) & & & $-0.0346^{* * *}$ & $-0.0532^{* * *}$ & $-0.0362^{* * *}$ & $-0.0504^{* * *}$ \\
\hline Children under 20 (ia) & & & $0.0350^{* *}$ & 0.00348 & $0.0429^{* * *}$ & 0.00919 \\
\hline Adults aged 20 to 64 (ia) & & & $-0.128^{* * *}$ & -0.0886 & $-0.109^{* * *}$ & -0.0730 \\
\hline Adults aged 60 and more (ia) & & & -0.107 & 0.0335 & -0.0184 & 0.0627 \\
\hline \multicolumn{7}{|l|}{ Single $(\mathrm{t}-1)$} \\
\hline Couple (t-1) & 0.0392 & 0.136 & 0.0988 & 0.134 & 0.0888 & $0.259^{* *}$ \\
\hline Couple with children (t-1) & $0.287^{* *}$ & $0.215^{*}$ & $0.330^{* * *}$ & $0.271^{* *}$ & $0.326^{* * *}$ & $0.338^{* * *}$ \\
\hline Monoparental Family (t-1) & $0.254^{*}$ & $0.205^{*}$ & $0.280^{* *}$ & $0.224^{*}$ & $0.311^{* * *}$ & $0.348^{* * *}$ \\
\hline Extended Family (t-1) & 0.141 & 0.0697 & $0.236^{*}$ & 0.131 & $0.210^{*}$ & $0.183^{*}$ \\
\hline \multicolumn{7}{|l|}{ Economic characteristics } \\
\hline $\mathrm{Nb}$ of cattle (t-1) & $-0.0118^{* * *}$ & -0.00394 & $-0.00816^{* * *}$ & -0.00276 & $-0.00597^{* * *}$ & $-0.00374^{*}$ \\
\hline $\mathrm{Nb}$ of porks $(\mathrm{t}-1)$ & $-0.0336^{* * *}$ & $-0.0185^{*}$ & $-0.0307^{* * *}$ & -0.0146 & $-0.0286^{* * *}$ & $-0.0178^{*}$ \\
\hline $\mathrm{Nb}$ of goats $(\mathrm{t}-1)$ & -0.000105 & 0.00186 & -0.00218 & 0.000327 & -0.00298 & $0.00467^{*}$ \\
\hline
\end{tabular}


$\mathrm{Nb}$ of poultry $(\mathrm{t}-1)$

Area owned (t-1)

Area owned (ia)

Share of crops in TI (ia)

Share of animal products in TI (ia)

Share of agricultural wage work in TI (ia)

Share of non agricultural activities in TI (ia)

Share of cash crops in TI(ia)

Net buyer (ia)

Shocks

Shock intensity on rice fields (ia)

Shock intensity on tuber fields (ia)

Shock intensity on maize fields (ia)

Constant

Year and year*area dummies

Statistics

Number of observations

Number of households

Log likelihood

$-0.000933^{* * *}$

$-0.00332^{* *}$

$-0.000970^{* * *}$

$0.512^{* * *}$

$-0.583^{* * *}$

$1.622^{* * *}$

$0.588^{* * *}$

$-4.504^{* * *}$

$0.124^{*}$

\section{$0.295^{*}$}

$0.434^{*}$

$1.605^{* * *}$

$0.262^{*}$

$-2.001 * * *$

0.0523

$-0.00282^{* * *}$

$-0.118$

$-1.504^{* * *}$
$1.149^{* * *}$

0.0102

$-5.004^{* * *}$

$0.295^{* * *}$

\subsection{0}

$0.250^{* * *}$

$-1.342^{* * *}$

$-1.512^{* * *}$

$0.256^{* * *}$

$-1.414^{* * *}$

9856

27478
9912

$-17637.0$
$-0.00268^{* * *}$

$-0.00629$

$-0.508^{* *}$

$1.721^{* * *}$

$-0.119$

$-2.389^{* * *}$

$0.197^{* * *}$

$-0.0729$

$166 * * *$

$0.188^{* * *}$

$-1.916^{* * *}$

model-Coefficients, ROR surveys, 1996-2006 
Regarding the ESPM specification, estimated coefficients are presented in Table 4. The coefficient vector associated to explanatory variables is different depending on the initial household poverty status $\left(\beta_{1} \neq \beta_{2}\right)$. Referring to the test of state dependence defined in section 3.2.6, the null hypothesis of no state dependency is clearly rejected. In other words, poor and non-poor households have different poverty propensity generating functions. The age and gender of the household head, the family structure, the number of children, the quantity of assets, the portfolio of activities and the riskiness of agricultural production affect poverty propensity in a different way depending on household poverty status.

Households with older household heads, more children and fewer active adults have higher risks to stay poor if they are already poor whereas these same characteristics are not correlated with higher risks of entering poverty if households are non-poor. In the same vein, being an extended family is correlated with a higher risk of staying poor if already poor whereas it is not correlated with higher risk of entering poverty if non-poor. These results indicate that non-poor households are more able to deal with a higher pressure on resources due to numerous household members than poor households. Female headship is correlated with lower poverty propensity when an household is non-poor but it has no impact on poverty propensity when an household is poor.

Regarding economic characteristics, owning more assets decreases both poverty persistence and poverty entry risk. However, it decreases more poverty propensity when the household is poor than when the household is non-poor. This result suggests that returns to assets are higher for poor households. The activity portfolio also has a different impact on poverty propensity depending on past poverty status. A higher share of animal products (milk, eggs, flesh, etc.) in total income decreases poverty propensity when poor but not when non-poor. This result may indicate that households with more diversified sources of income have a higher poverty exit propensity. We also observe that the share of cash crops decreases far more poverty propensity for the poor than for the non-poor. Finally, the average riskiness of tuber production increase more the poor poverty propensity than the non-poor poverty propensity indicating that poor households are less well protected against shocks on this staple crop.

Being a net buyer of rice increases poverty propensity for the poor but has no impact on the poverty propensity of non-poor households. It indicates that poor households are more likely to face price and availability issues regarding their purchases of rice.

Moreover, demographic events do not affect poverty propensity in the same manner depending on poverty status. Changes in family structure decrease poverty propensity of poor households whereas it has no impact on non-poor households. On the opposite, transition from male to female headship is found to increase poverty propensity if an household is non-poor but has no consequences on poverty propensity if an household is already poor. Note that such a transition can be interpreted as the death or departure of the male household head.

Genuine state dependency, calculated as in equation (32), is 0.48 when calculated on the model with sample selection and Chamberlain-Wooldrige treatment of individual het- 


\begin{tabular}{rccc}
\hline & Low GSP $(; 0,25)$ & Middle GSP $(0,25-0,5)$ & High GSP $($ ¿0,5) \\
\hline Age & 47 & 47 & 44 \\
Male & 83 & & 82 \\
Female & 17 & 20 & 18 \\
Head gender (\%) & & & \\
Single & 6.51 & 3.73 & 3.00 \\
Couple & 6.54 & 3.60 & 3.98 \\
Family structure (\%) & 43.52 & 8.63 & 49.94 \\
Couple with children & 8.00 & 37.75 & 8.62 \\
Monoparental Family & 35.42 & 5,6 & 34.46 \\
Extended Family & 5 & 3,3 & 5,6 \\
Family size & 2,5 & 65 & 3,5 \\
Number of children & 106 & 65 & 52 \\
Area owned (are) & 75 & 3 & 64 \\
Land owner (\%) & 5 & 80 & 3 \\
Number of cattle & 81 & 26 & 76 \\
Livestock owner (\%) & 21 & & 30 \\
No education (\%) & & & \\
\hline
\end{tabular}

Table 5: Households characteritics by Genuine State Dependence level, ROR surveys, 1996-2006

erogeneity. In other words, our model predicts that a poor household at $t-1$ has 0.48 percentage points more risk to be poor at $t$ than a non-poor household. Table 5 gives some selected households characteristics by GSD level. State dependence is larger for less educated households with larger family size, especially more children, and with lower assets in the form of land and livestock. It means that they are more likely to be subject to poverty traps.

\subsection{Individual heterogeneity}




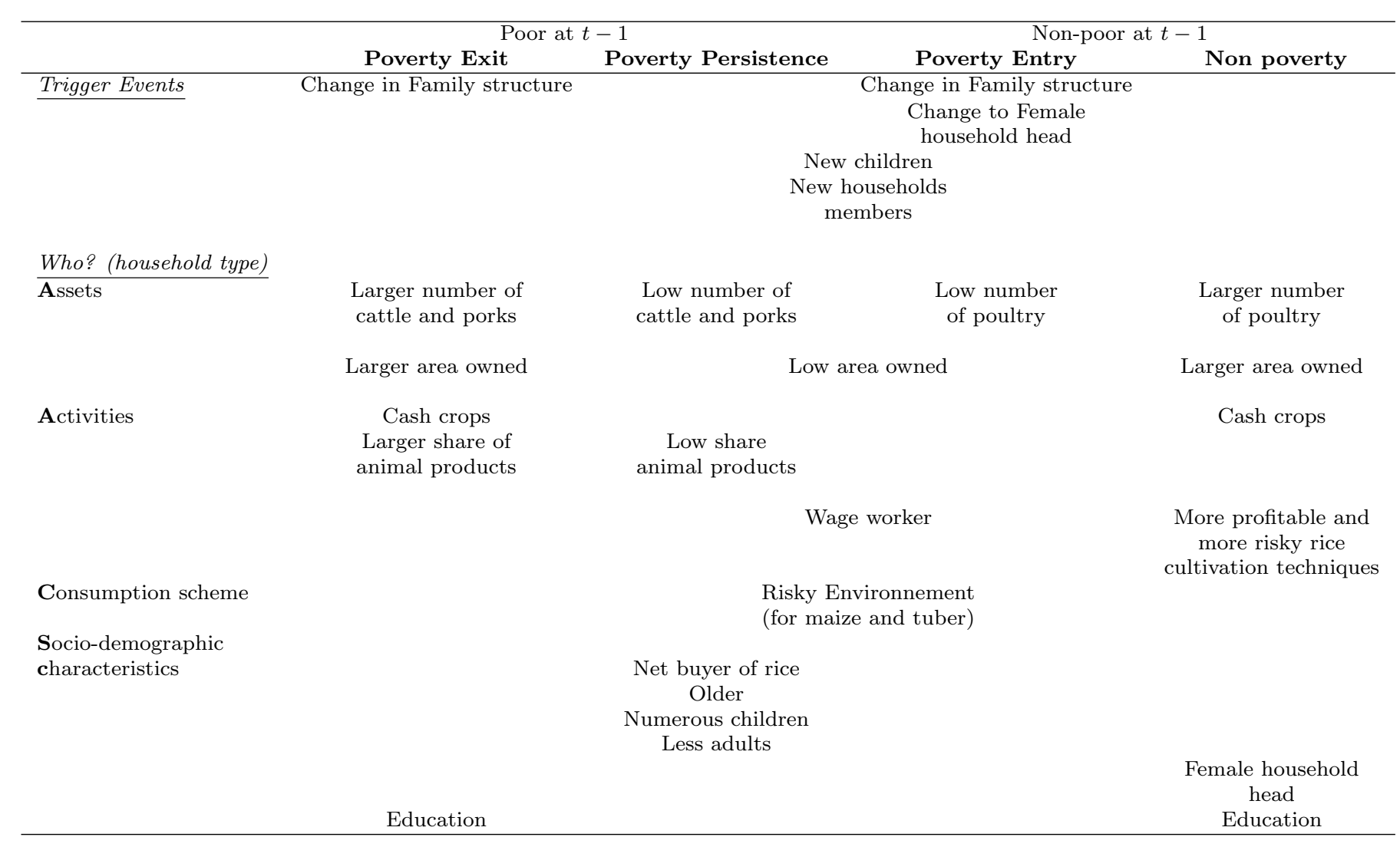

Table 6: Summary of the endogenous switching probit model results, ROR surveys, 1996-2006 
The results of the ESPM and REDP are summarized in Tables 6 and 7, Detailed results are presented in Appendix in Tables 10 and 9.

Regarding the interpretation of estimation results, the ESPM allows us to identify determinants of poverty persistence (chronic poverty), poverty entry (transient poverty) and poverty in general. Explanatory variables that determine both probability persistence and probability entry are determinants of poverty in general, independently of the initial poverty status, i.e., independently of the dynamics. The variables that significantly increase the probability to stay poor (by not the entry probability) are determinants of poverty persistence. The variables that significantly increase the probability to enter poverty (but not the probability to stay poor) are determinants of poverty entry. The estimation results of the REDP model allows us to determine the determinants of poverty risk but does not allow to distinguish between poverty persistence and poverty entry determinants.

Estimation of the ESPM show that poverty persistence is linked to the demographic characteristics of the household and the nature of income generating activities. Poverty persistence is more likely for households with elderly heads and large dependency ratios. Extended family are also more likely to be persistently poor. Poverty persistence also appears to be correlated with a lower share of income coming from animal products. This result can be interpreted as follows. Households having a more diversified income are less prone to poverty persistence. Moreover, change of family structure increases poverty exit probability.

Regarding the determinants of poverty entry, the probability of entering poverty is lower if the household is female-headed. On the other hand, when there is a transition from male to female headship, the probability to enter poverty increases as indicated by the APEs of household gender in level 9

Most of the variables included in the regression are significant in both equations meaning that they determine poverty in general independently of the dynamics. Regarding socioeconomic variables, single individuals and couples without children have better chance to be non-poor compared to other families. Couples with children have the highest risk of poverty compared to other families, followed by monoparental families. Increases in the number of households members raise the probability of poverty. It indeed put pressure on resources. This results are confirmed by the REDP estimation results.

Education is correlated with substantially lower poverty risk in both the ESPM and REDP. It is worth noting that the APE of household head education is very similar for poor and non-poor households in the ESPM. It thus suggests that education is a good poverty reduction leverage. The education of the wife also reduces poverty risk. The returns to education are a bit better for women in non-poor households. They probably have access

\footnotetext{
${ }^{9}$ This result may seem paradoxical given the results obtained with the same variable averaged over time. However, we have to refer to the interpretation of the parameters of $\bar{x}_{i}$ and $x_{i t}$ previously described. Female-headed households are less likely to be chronically poor. But when the household head changes to a woman, probably because the man died or left, an household is more likely to enter poverty the following year.
} 


\begin{tabular}{lc}
\hline & Poverty risk \\
\hline Assets & - \\
Livestock & - \\
Land & \\
Activities (share in total income) & - \\
Other crops than rice & - \\
Non agricultural activities & - \\
Cash crops & + \\
Wage work & + \\
Shocks on rice fields & - \\
Socio-demographic characteristics & - \\
Age & + \\
Household size & - \\
Dependency ratio & $1:$ single \\
Education & $2:$ extended family \\
Family structure & $3:$ couple \\
in ascending order & $4:$ monoparental family \\
of poverty risk & couples with children \\
& Activities riskiness \\
& - \\
Rice & + \\
Maize & + \\
Tuber & + \\
Socio-demographic shocks & + \\
Increanse in household size & \\
Increase in the dependency ratio & + \\
\hline
\end{tabular}

Table 7: Summary of the random effect dynamic probit results, ROR surveys, 1996-2006 
to a larger set of activities than poor women.

Regarding economic characteristics, results are almost similar in the two models. Households with a large share of income coming from agricultural wage work have significantly higher risks to be poor. It has indeed been shown that poor households rely more on agricultural wage work than richer households and that agricultural wage are very low and varying in Madagascar (Bockel and Dabat, 2001). On the contrary, the share of cash crops in total income is correlated with dramatically lower poverty risks. Moreover the higher the size of livestock and land owned by a household, the lower the poverty propensity.

The average riskiness of tuber and maize plantations is correlated with higher poverty risk. The parameter associated to mean damages on these two crops is indeed positive and significant. However, punctually suffering a shock on these crops does not automatically entails poverty. Surprisingly, the average riskiness in rice production is not correlated with higher poverty risk. Higher riskiness is even correlated with lower poverty risk in some specification. This last result may appear odd. An explanation is that rich households choose more risky production techniques for rice cultivation and thus have more important damages on their fields on average. More risky techniques are also more profitable and thus reduces poverty risk. We however observe that the poverty risk increases in response to a shock on rice fields. The latest effect refers to the APE of the rice shock variable in level whereas the last refers to the rice shock variable averaged over time.

\subsection{Endogeneity of Initial Poverty Status}

The estimation of cross correlation, $\rho$, between the unobservables in the initial poverty status equation (10) and the poverty transition equation (11) provides a test for initial poverty status exogeneity.

The cross-equations correlation of unobservables is significant at a nine percent level for the poverty entry model and at a two percent level for the poverty persistence model (see $\rho$ and the critical probabilities associated in Table 10). The estimates are sizable since $\hat{\rho}_{1}=+0.39$ and $\hat{\rho}_{2}=-0.31$. Unobservables increasing the probability to be poor at $t-1$ also increase the probability of being poor at $t$. The negative sign for $\rho_{2}$ tells the same story. Unobservables increasing the probability to be non-poor in the first place decrease the probability of being poor. If initial conditions are ignored, poverty persistence probability is estimated on a sample with a conditional poverty propensity higher than the relevant population. Poverty persistence is thereby overestimated. On the other hand, if initial conditions are ignored in the poverty entry model, it is estimated on a sample where the conditional poverty propensity is lower than in the relevant population. Poverty entry rates are thereby underestimated .

The initial poverty status is instrumented with crop shock at $t-2$. We verify that this variable is not correlated with poverty transitions by introducing it in the main regression equation. It is not significant and the critical probability associated to its coefficient is 0.83 . On the other hand, it is significant in the selection equation meaning that it is correlated 


\begin{tabular}{|c|c|c|c|c|}
\hline $\begin{array}{l}\text { Household } \\
\text { type }\end{array}$ & Description & $\begin{array}{l}\text { Poverty persitence rate } \\
(E S P M)\end{array}$ & Poverty entry rate & $\begin{array}{l}\text { Poverty risk } \\
\text { (REDP model) }\end{array}$ \\
\hline (1) & $\begin{array}{l}\text { Male household head } \\
\text { Couple with } 2 \text { children, } \\
\text { living with one elder. } \\
\text { No shocks on crops } \\
\text { Net seller of rice }\end{array}$ & 0,75 & 0,62 & 0,82 \\
\hline$(2)$ & $\begin{array}{l}\text { As (1) except change to } \\
\text { female household head } \\
\text { and monoparental family }\end{array}$ & 0,75 & 0,80 & 0,84 \\
\hline$(3)$ & As $(1)+2$ children & 0,83 & 0,75 & 0,89 \\
\hline (4) & $\begin{array}{l}\text { As (1) except net } \\
\text { net buyer of rice }\end{array}$ & 84,00 & 0,62 & 0,87 \\
\hline$(5)$ & As (1) except no education & 0,82 & 0,67 & 0,89 \\
\hline (6) & As (1) except 4 children & 0,78 & 0,63 & 0,83 \\
\hline (7) & $\begin{array}{l}\text { As }(1) \text { except rice harvest } \\
\text { reduced detroyed }\end{array}$ & 0,75 & 0,62 & 0,86 \\
\hline (8) & $\begin{array}{l}\text { Female household head, } \\
\text { monoparental family } \\
\text { other characteristics } \\
\text { like (1) }\end{array}$ & 0,75 & 0,55 & 0,82 \\
\hline (9) & As $(8)+2$ children & 0,83 & 0,65 & 0,89 \\
\hline (10) & $\begin{array}{l}\text { As }(8) \text { except } \\
\text { net buyer of rice }\end{array}$ & 0,79 & 0,58 & 0,87 \\
\hline (11) & As (8) except no education & 0,82 & 0,65 & 0,89 \\
\hline
\end{tabular}

Table 8: Predicted persistence and poverty entry rates and predicted poverty risk, ROR surveys 1999-2006

with initial poverty status 10

\subsection{Rates of Poverty persistence and Poverty Entry Among Malagasy ROR Households}

Heterogeneity in poverty persistence, poverty entry rates and poverty risk can be examined by looking at predicted poverty persistence, predicted entry rate and predicted poverty risk. Predicted poverty persistence and entry rate are obtained as in equations (19) and (20) for the ESPM. Predicted poverty risk is obtained by using the estimated parameter for the REDP model. Non-significant variables are ignored when predicting poverty risks.

\footnotetext{
${ }^{10}$ We are not able to run the usual test of overidentifying restrictions since we cannot retrieve residuals from the probit estimation
} 
We present here the predicted poverty risks for various household types in Table 8 , It is worth noting that our regression framework allows us to calculate poverty risks of different types of households. We thus obtain very disaggregated measures of poverty that account for poverty dynamics. This may be very useful to identify household types that are more vulnerable to chronic or transient poverty.

The reference household is headed by a male, in couple with two children and one elder at home. He is a net seller of rice and does not suffer from any crop shocks. Its poverty persistence rate is .75 whereas its poverty entry rate is 0.62 .

Demographic shocks have important consequences. The birth of children dramatically increases both poverty entry and poverty persistence rates (line 3 of table 8). It increases poverty persistence risk by 8 percentage points, poverty entry risk by 13 percentage points for male-headed households and by 10 percentage points for female-headed households. The increase in poverty risk is 7 percentage points with the REDP model. Social protection thus has to be targeted toward couples with babies or young children. This result also suggests family planning could be an important poverty reduction tool. The death or departure of the male household head, i.e. the transition from male to female headship in our model, increases dramatically poverty entry risk but does not affect poverty persistence risk (line 2 of Table 8 ).

The lack of education increases household poverty persistence and entry risks by five percentage points. The increase is about seven percentage points with the REDP. As previously mentioned, education appear as a good poverty reduction leverage for poverty in general.

Female-headed households have, on the one hand, similar poverty persistence rates and overall poverty risk than male-headed households and on the other hand, lower poverty entry rates than male-headed households. This results suggests that female-headed households are not more vulnerable than other groups of people. It would suggest that targeting female-headed households is not necessary when designing poverty reduction tools.

Being a net buyer of rice increases poverty persistence risk by nine percentage points and overall poverty risk by five percentage points. It has on the other hand no impact on poverty entry risk.

\section{Conclusions}

Referring to the state dependence and individual heterogeneity mechanisms defined in the introduction, we find that high poverty persistence rates in our rural Malagasy household sample arise from both the consequences of past poverty and household adverse characteristics making them more poverty prone.

Persistently poor households have larger dependency ratios, are less educated, have less endowments and carry out less profitable activities. These weaknesses have been well identified in the Malagasy poverty reduction strategy paper. It indeed promotes reduction 
in family size through family planning, universal primary education and high value-added agriculture.

On the other hand, poverty has a genuine causal effect on future poverty. We thus confirm that state dependence exists in rural areas of Madagascar, at least in our sample. This results brings, on the one hand, elements on poverty reduction policies in rural Madagascar and, on the other hand, insights for intertemporal poverty measurement.

First, our result underlines the necessity to limit both occurrence and duration of poverty spells since it is likely to push households in poverty traps. Poverty is likely to impact both observed households characteristics such as the choice of income generating activities, the production technology, the ability to cope with shocks (Thomas, 2011), the level of assets (Mills et al., 2004) as well as unobserved characteristics such as motivation. It is thus important to early identify, on one hand, households that are likely to enter poverty, and on the other hand, households that have long poverty spells. Without early intervention against poverty, it gets harder (and more costly) to address the problem of poverty.

Second, state dependence in poverty dynamics also has implications for poverty measurement. It makes necessary to take household living standard trajectory into account. Static poverty indexes miss an important part of the story. Two poor households have the same weight in the poverty index independently of the time they have spent below the poverty line 11 In other words, they weight the same in the poverty index independently of their probability to exit poverty. Two poor households may well be in very different poverty situations depending of their past poverty experience. The first household can have low poverty persistence risk and good exit chances whereas the second can have high poverty persistence risk and low chances of exit. Incorporating poverty dynamics in the measure of poverty is thus really needed to have a more detailed picture of the poverty situation. The recent poverty literature has mainly focused on the multidimensionality in assessing living standards and neglected the time dimension. Static poverty indicators are often averaged over time without careful examination of underlying assumptions regarding the aggregation of poverty experiences over time. A recent theoretical literature has tried to establish a framework for intertemporal poverty measurement ( Calvo and Dercon, 2007; Porter and Quinn, 2008)). In practice, the choice between the different alternatives is an empirical matter. Compensation of poverty spells by non-poverty spells and duration of the adverse impacts of a poverty spell namely depend on the efficiency of existing credit and insurance services.

Actually, the predicted value of poverty risks by our econometric models provides interesting measures of poverty. The pairs of probability formed by the predicted poverty persistence and entry rate in the ESPM, one hand, and the predicted probability to be poor in the REDP model, on the other hand, model takes past poverty into account. It

\footnotetext{
${ }^{11}$ This is corrrect if the poverty index is the poverty headcount. If the poverty gap or the squared poverty gap squared is used, two households have the same weights if they have the same poverty depth.
} 
has two main advantages. First, the impact of past poverty is estimated so that we do not pass arbitrary judgement on the size of the impact of past on future poverty. Second, these measures are decomposable in the space and time dimensions and in any subgroup of the population. Evolution of poverty over time can be thus studied. Comparison between areas can be made. It is also possible to compare the distribution of predicted probabilities by type of households such as couples with children, land owners, wage-workers, etc .

The main limitation of our study is that the mechanisms through which past poverty affects current poverty are not explicitly modelized. A further direction of research is to explicitly specify feedback effects of past poverty on the portfolio of activities and the level of assets used as risk coping strategies. In practice, it implies to estimate one equation for each variable affected by poverty and estimate it jointly with the main equation. Biewen (2009) performed such an analysis on German household data. Another limitation of our study is that the determinants included in the regressions are limited. For example, geographic variables such as infrastructures and social services are only controlled by time and area dummies and by the household time-invariant effect. Their impact is thus not quantified. Finally we do not investigate the impact of the duration spent below the poverty line as such. We only estimate the impact of past poverty status. In other words, we study state dependence but not duration dependence. Estimating duration model, or increasing the order of our Markov chain could improve our analysis.

\section{References}

Tony Addison, David Hulme, and Ravi Kanbur. Poverty Dynamics, Interdisciplinary perspectives. Oxford University Press, 2009.

Yonas Alem. The dynamics and persistence of urban poverty: Panel data evidence from ethiopia. Technical report, University of Gothenburg, Sweden, 2011.

Mary Jo Bane and David Ellwood. Slipping into and out of poverty: The dynamics of spells. Journal of Human Resources, 21(1):1-23, 1986.

Christopher Barrett, Paswel Marenya, John Mcpeak, Bart Minten, Festus Murithi, Willis Oluoch-Kosura, Frank Place, Jean Randrianarisoa, Jhon Rasambainarivo, and Justine Wangila. Welfare dynamics in rural kenya and madagascar. The Journal of Development Studies, 42(2):248-277, February 2006.

B Baulch and B Hodinott. Economic mobility and poverty dynamics in developing countries. Journal of Development Studies, 36(6(1)), 2000.

Bob Baulch. Why Poverty persists? Edward Elgar Publishing Limited, 2011.

Jean-Etienne Bidou and Isabelle Droy. Dcrire la construction temporelle des vulnrabilits: observatoires ruraux et analyse historique des moyens d'existence dans le sud malgache. 
Risques et environnement: recherches interdisciplinaires sur la vulnrabilit des socits. l'Harmattan, 2009.

Martin Biewen. Measuring state dependence in individual poverty histories when there is feedback to employment status and household composition. Journal of Applied Econometrics, 24(429):1095 - 1116, 2009.

Louis Bockel and Marie-Hlne Dabat. Amliorer la productivit du travail dans la riziculture pour lutter contre la pauvret madagascar. In Sminaire international "La pauvret Madagascar : tat des lieux, facteurs explicatifs et politiques de rduction", Antananarivo, fvrier 20012001.

Cesar Calvo and Stefan Dercon. Chronic poverty and all that: The measurement of poverty over time. CSAE Working Paper Series 2007-04, Centre for the Study of African Economies, University of Oxford, 2007.

Lorenzo Cappellari and Stephen P. Jenkins. Modelling low income transitions. Journal of Applied Econometrics, 19(5):593-610, 2004.

Lorenzo Cappellari and Stephen P. Jenkins. The dynamics of social assistance receipt: Measurement and modelling issues, with an application to britain. IZA Discussion Papers 3765, Institute for the Study of Labor (IZA), October 2008.

Lorenzo Cappellari. Earnings mobility among italian low-paid workers. Journal of Population Economics, 20(2):465-482, April 2007.

Gary Chamberlain. Analysis of covariance with qualitative data. Review of Economic Studies, 47(1):225-38, January 1980.

A Deaton and M Grosh. Designing Household Survey Questionnaires for Developing Countries: Lessons from 15 Years of the Living Standards Measurement Study, volume 1, chapter 3 Consumption. Washington, DC: World Bank., 2000.

Stefan Dercon and Luc Christiaensen. Consumption risk, technology adoption, and poverty traps : evidence from ethiopia. Journal of Development Economics, 94 (1)(4257), June 2011.

Stefan Dercon and Joseph Shapiro. Moving on, staying behind, getting lost : Lessons on poverty mobility from longitudinal data. Working Papers Series 075, Global Poverty Research Group, 2007.

Francesco Devicienti. Poverty persistence in britain: A multivariate analysis using the bhps, 1991-1997. Journal of Economics, 9(1):307-340, 2002. 
Isabelle Droy, Raphal Ratovoarinony, and Franois Roubaud. Les observatoires ruraux madagascar: une mthodologie originale pour le suivi des campagnes. Revue STATECO, 95-96-97:123-140, 2001.

Isabelle Droy, Jean-Etienne Bidou, Jossie Randriamiandrisoa, and Anne-Claire Thomas. Madagascar face au dfis des Objectifs du Millnaire pour le Dveloppement, chapter 2: Une pauvret rurale tendue et multiforme. IRD Editions., 2010.

Greg J. Duncan. Poverty dynamics in eight countries. Journal of Population Economics, 6:215-234, 1993.

Ousmane Faye, Nizamul Islam, and Eliya Msiyaphazi Zulu. Poverty dynamics in nairobi's slums: Testing for true state dependence and heterogeneity effects. November 2011.

A Giraldo, E. Rettore, and UT Rivellato. The persistence of poverty: true state dependence or unobserved heterogeneity? some evidence from the italian survey on household income and wealth. Technical report, Paper presented at the 27th General Conference of the International Association for Research in Income and Wealth, Stockholm, 2002.

Claire Gondard-Delcroix. Dynamiques de pauvret en milieu rural malgache. Documents de travail 111, Groupe d'Economie du Dveloppement de l'Universit Montesquieu Bordeaux IV, April 2005.

Claire Gondard-Delcroix. Risque, pluriactivit rurale et dynamiques de pauvret en milieu rural malgache. Journal of Human Development and Capabilities, 10(1):77-101, 2009.

Flore Gubert and Anne-Sophie Robilliard. Dynamics of rural poverty in madagscar. Technical report, Dial, 2003.

Flore Gubert and Anne-Sophie Robilliard. Risk and schooling decisions in rural madagascar: A panel data-analysis. Journal of African Economies, 17(2):207-238, March 2008

James J Heckman. The incidental parameters problem and the problem of initial conditions in estimating a discrete time-discrete data stochastic process. Structural Analysis of Discrete Data with Econometric Applications. MIT Press, Cambridge, MA., 1981.

INSTAT. Enqute priodique auprs des mnages 1997- rapport principal. Technical report, INSTAT, Fvrier 1999.

INSTAT. Notes techniques sur la construction du profil de pauvrette 2001 et l'analyse de la dynamique de la pauvret entre 1999 et 2001. Technical report, Antananarivo, Madagascar., 2002.

INSTAT. Enqute priodique auprs des mnages 2002- rapport principal. Technical report, INSTAT, November 2003. 
INSTAT. Enqute priodique auprs des mnages 2004-rapport principal. Technical report, INSTAT, Janvier 2004.

INSTAT. Enqute priodique auprs des mnages 2005 -rapport principal. Technical report, INSTAT, 2006.

INSTAT. Enqute priodique auprs des mnages 2010 -rapport principal. Technical report, INSTAT, 2011.

Nizamul Islam and Abebe Shimless. Poverty dynamics in ethiopia: state dependance and transitory shocks. Working papers in Economics 260, University of Gothenburg, Sweden, 2007.

Jyotsna Jalan and Martin Ravallion. Determinants of transient and chronic poverty : evidence from rural china. Policy Research Working Paper Series 1936, The World Bank, June 1998.

Stephen P. Jenkins and John A. Rigg. The dynamics of poverty in britain. Research report 157, Department for Work and Pensions, 2001. with the assistance of Francesco Devicienti.

Tony Lancaster. The Econometric Analysis of Transition Data. 1990.

Bradford Mills, Carlo del Ninno, and Harivelo Rajemison. Commune shocks, household assets, and economic well-being in madagascar. In Selected Paper for Presentation at American Agricultural Economics Association Meetings, Denver Colorado, 2004.

Christopher D. Orme. The initial conditions problem and twostep estimation in discrete panel data models. Discussion Paper 9633, School of Social Sciences, University of Manchester, http://personalpages.manchester.ac.uk/staff/chris.orme/documents/ResearchJune 1997. Revised version, 2001, retitled as: Two-Steps inference in dynamic non-linear panel data models.

H Oxley, TT Dang, and P Antolin. Poverty dynamics in six oecd countries. OECD Economic Studies 30:7-52, OECD, 2000.

Catherine Porter and Natalie Quinn. Intertemporal poverty measurement: Tradeoffs and policy options. CSAE Working Paper Series 2008-21, Centre for the Study of African Economies, University of Oxford, 2008.

M. Ravallion. Poverty comparisons - a guide to concepts and methods. Papers 88, World Bank - Living Standards Measurement, 1992.

J Razafindravonona, D. Stifel, and S. Paternostro. Evolution de la pauvret madagascar : 1993-1999. Technical report, INSTAT, 2001. 
Rafael Perez Ribas, Ana Flvia Machado, and Andr Braz Golgher. Fluctuations and persistence in poverty: a transient -chronic decomposition model for pseudo-panel data. CEDEPLAR/FACE/UFMG, Belo Horizonte, UFMG/Cedeplar- Texto para discusso ; 289: 34p. 2006.

A. Stevens. Climbing out of poverty, falling back in: Measuring the persistence of poverty over multiple spells. Journal of Human Resources, 34:557-588, 1999.

Anne-Claire Thomas. Poverty, Risk and Insurance in Rural Madagascar. PhD thesis, University of Louvain, Belgium, 2011.

Jeffrey M. Wooldridge. Econometric Analysis of Cross Section and Panel Data. The MIT Press, October 2001.

Jeffrey M. Wooldridge. Simple solutions to the initial conditions problem in dynamic, non-linear panel data models with unobserved heterogeneity. J. Appl. Econ., 20:39-54, 2005 .

WorldBank. Worlddatabank. http://databank.worldbank.org/ddp/home.do, 2011.

S. Yaqub. Poverty dynamics in developing countries. Technical report, IDS Development Bibliography, University of Sussex, 2000.

\section{Appendix}




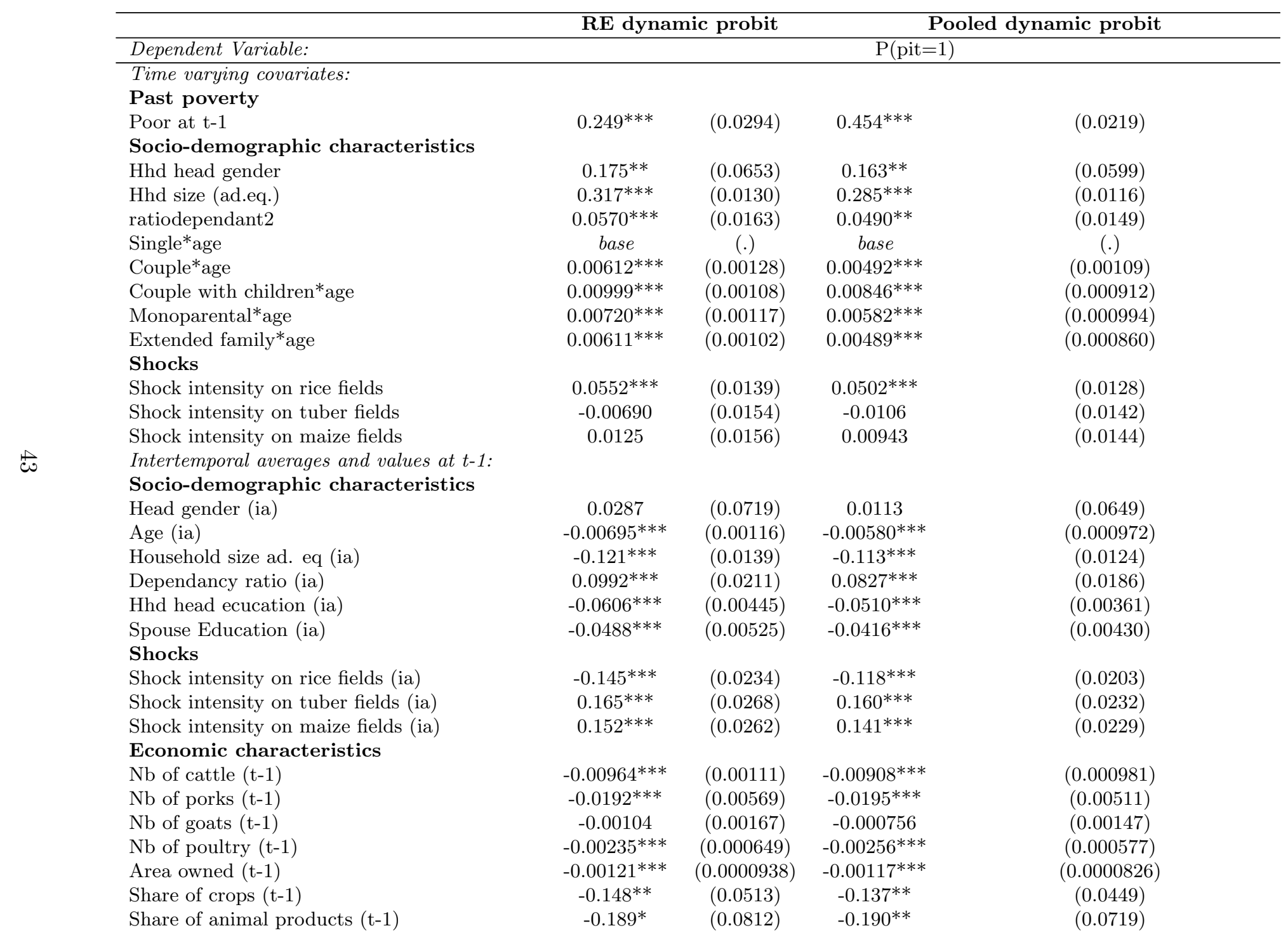




$\begin{array}{lcccc}\text { Share of agricultural wage work in TI (t-1) } & 0.343^{* * *} & (0.0696) & 0.334^{* * *} & (0.0618) \\ \text { Share of non agricultural activities in TI (t-1) } & -0.146^{* *} & (0.0457) & -0.141^{* * *} & (0.0401) \\ \text { Share of cash crops in TI (t-1) } & -2.609^{* * *} & (0.167) & -2.367^{* * *} & (0.142) \\ \text { Net buyer (t-1) } & 0.216^{* * *} & (0.0223) & 0.195^{* * *} & (0.0199) \\ \begin{array}{l}\text { Initial conditions: } \\ \text { Initially poor }\end{array} & 0.388^{* * *} & (0.0282) & 0.239^{* * *} & (0.0205)\end{array}$

Initial poverty gap

included

Year dummie

Statistics

Number of observation

Number of households

Correlation between the residuals of

the main and the residual equation (rho)

Log likelihood

$38967 \quad 38967$

15453

0.196

$-15265.3$

Table 9: Average partial effect- Dynamic Random Effect Probit, ROR

surveys, 1996-2006 


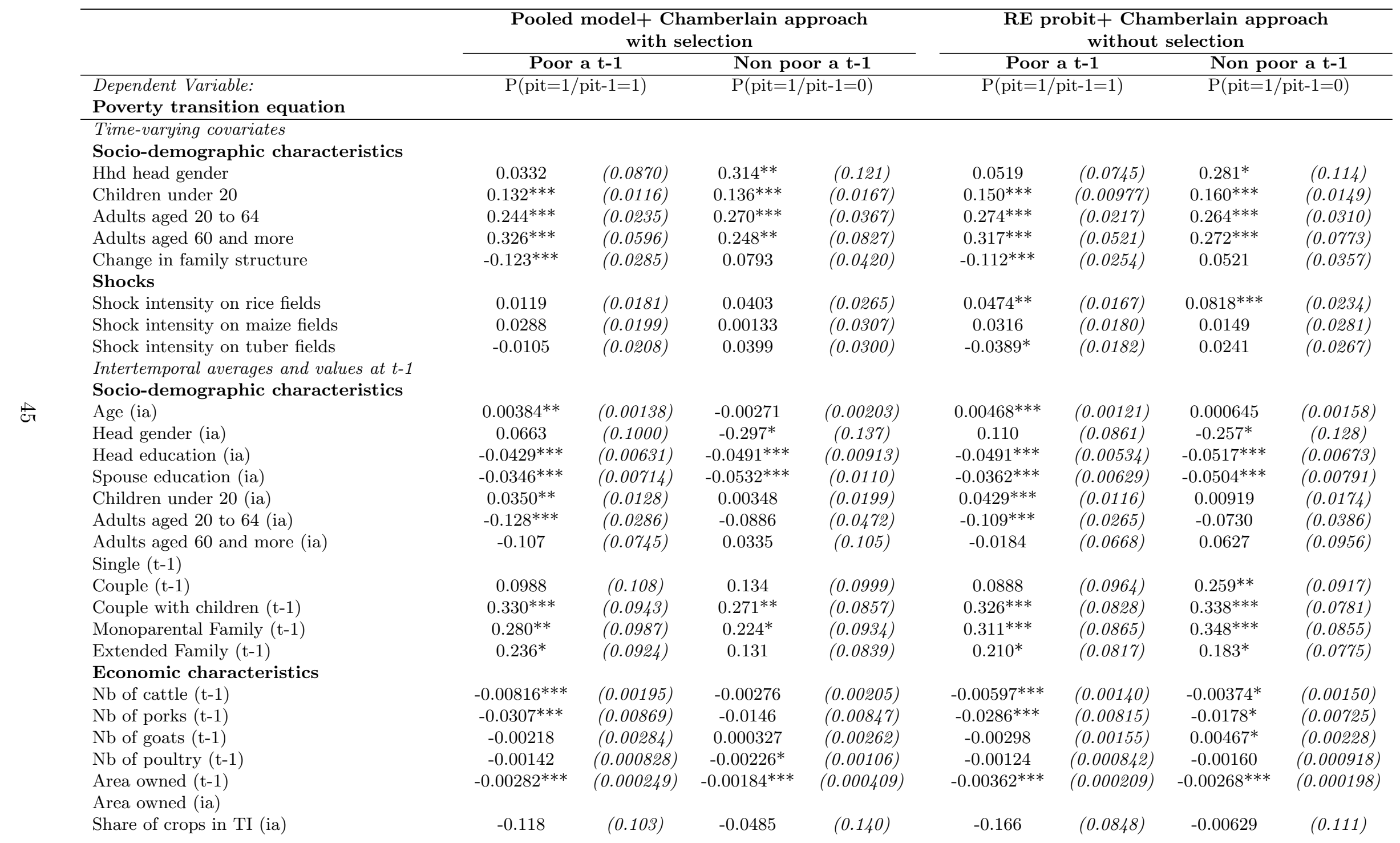




\begin{tabular}{|c|c|c|c|c|c|c|c|c|}
\hline Share of animal products in TI (ia) & $-1.504^{* * *}$ & $(0.177)$ & -0.270 & $(0.232)$ & $-1.870^{* * *}$ & $(0.142)$ & $-0.508^{* *}$ & $(0.185)$ \\
\hline Share of agricultural wage work in TI (ia) & $1.149^{* * *}$ & $(0.157)$ & $1.248^{* * *}$ & $(0.235)$ & $1.377^{* * *}$ & $(0.131)$ & $1.721^{* * *}$ & $(0.198)$ \\
\hline Share of non agricultural activities in TI (ia) & 0.0102 & $(0.0949)$ & 0.0334 & $(0.130)$ & -0.0806 & $(0.0784)$ & -0.119 & $(0.102)$ \\
\hline Share of cash crops in TI(ia) & $-5.004^{* * *}$ & $(0.381)$ & $-2.344^{* * *}$ & $(0.323)$ & $-3.998^{* * *}$ & $(0.288)$ & $-2.389^{* * *}$ & $(0.270)$ \\
\hline Net buyer (ia) & $0.295^{* * *}$ & $(0.0558)$ & 0.110 & $(0.0776)$ & $0.332^{* * *}$ & $(0.0438)$ & $0.197^{* * *}$ & $(0.0574)$ \\
\hline Shock intensity on rice fields (ia) & 0.0270 & $(0.0345)$ & -0.0892 & $(0.0491)$ & $-0.0655^{*}$ & $(0.0289)$ & -0.0729 & $(0.0387)$ \\
\hline Shock intensity on tuber fields (ia) & $0.250^{* * *}$ & $(0.0404)$ & $0.241^{* * *}$ & $(0.0575)$ & $0.242^{* * *}$ & $(0.0325)$ & $0.166^{* * *}$ & $(0.0473)$ \\
\hline Shock intensity on maize fields (ia) & $0.256^{* * *}$ & $(0.0396)$ & $0.150 * *$ & $(0.0536)$ & $0.239^{* * *}$ & $(0.0315)$ & $0.188^{* * *}$ & $(0.0460)$ \\
\hline \multicolumn{9}{|l|}{ Year and year*area dummies } \\
\hline \multicolumn{9}{|l|}{ Basis poverty status equation } \\
\hline Change in hhd size (t-2 to t- 1$)$ & $0.103^{* * *}$ & $(0.00750)$ & $-0.101^{* * *}$ & $(0.00746)$ & & & & \\
\hline Change in hhd gender ( $\mathrm{t}-2$ to $\mathrm{t}-1$ ) & 0.0513 & $(0.0446)$ & -0.0683 & $(0.0419)$ & & & & \\
\hline Shock on fields (t-2) & $0.0955^{* * *}$ & $(0.0208)$ & $-0.0817 * * *$ & $(0.0208)$ & & & & \\
\hline \multicolumn{9}{|l|}{ Statistics } \\
\hline Number of observations & 27422 & & 27478 & & 32145 & & 10954 & \\
\hline Number of households & 9856 & & 9912 & & 12521 & & 7643 & \\
\hline Genuine state dependance (a) & \multicolumn{4}{|c|}{0,476} & \multicolumn{4}{|c|}{0,111} \\
\hline$\zeta(\mathrm{b})$ & & & & & 0.184 & & 0.186 & \\
\hline$\rho$ (c) and critical probability in italic & 0.390 & 0.0229 & -0.310 & 0.0856 & & & & \\
\hline
\end{tabular}

Average partial effects, Standard errors in parentheses, ${ }^{*} \mathrm{p}_{i} 0.05,{ }^{* *} \mathrm{p}_{i} 0.01, * * * \mathrm{p} i 0.001,(\mathrm{a})$ Sample mean of $\mathrm{P}(\mathrm{pit}=1 / \mathrm{pit}-1=1)-\mathrm{P}(\mathrm{pit}=1 / \mathrm{pit}-1=0)$

(b):proportion of the total variance contributed by the panel-level variance component, (c) Correlation between the error terms of main and selection equations Table 10: Average partial effects- Endogenous switching probit model,

ROR surveys, 1996-2006 


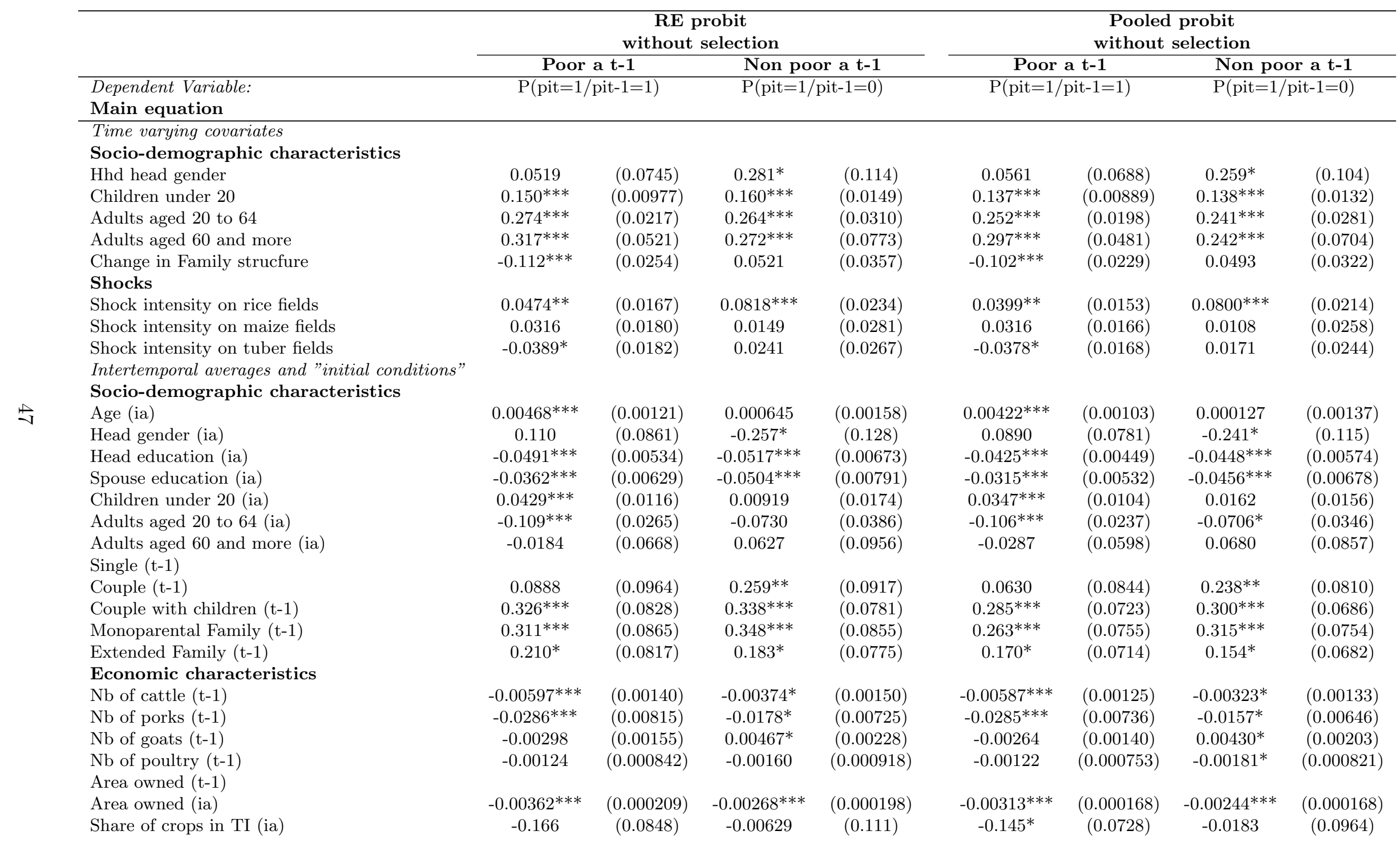




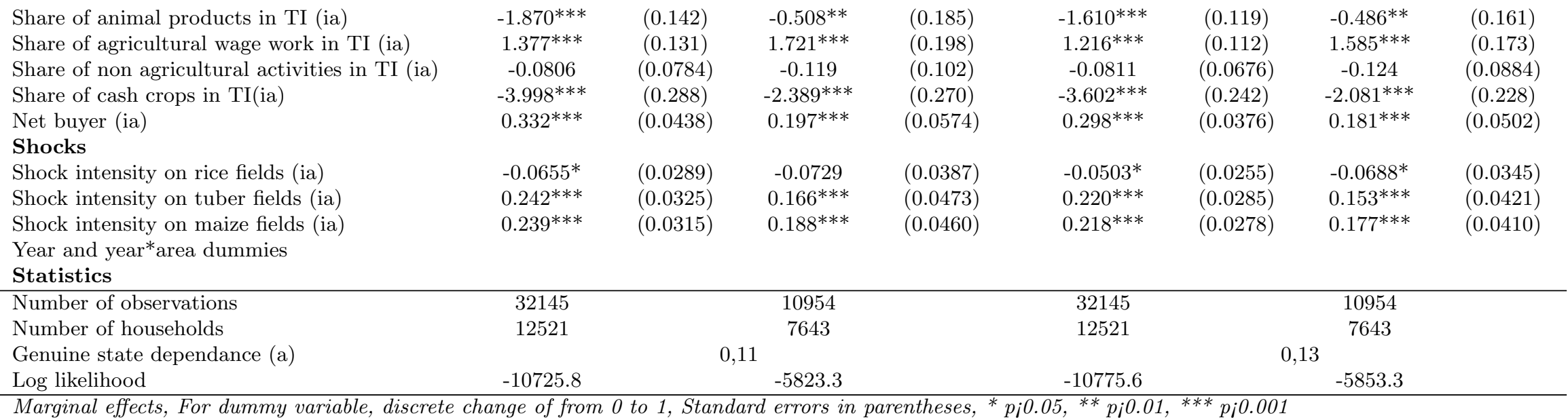

Marginal effects, For dummy variable, discrete change of from 0 to 1 , Standard errors in parentheses, ${ }^{*} p_{i} 0.05,{ }^{* *} p_{i} 0.01,{ }^{* * *} p_{i} 0.001$

(a) Sample mean of $P($ pit=1/pit-1=1)- $P($ pit=1/pit-1=0)

Table 11: Average partial effects- Endogenous switching probit model

without selection, ROR surveys, 1996-2006 


\begin{tabular}{lcc}
\hline & & $\begin{array}{c}\text { Pooled model } \\
\text { with selection }\end{array}$ \\
\hline Dependent Variable: & Poor a t-1 & Non poor a t-1 \\
\hline
\end{tabular}

Main equation

Time-varying covariates

Socio-demographic characteristics

Hhd head gender

Hhd head age

Head education

Spouse education

Children under 20

Adults aged 20 to 64

Adults aged 60 and more

Shocks

Shock intensity on rice fields

Shock intensity on maize fields

Shock intensity on tuber fields

$\begin{array}{cccc}0.0855^{*} & (0.0415) & 0.0558 & (0.0582) \\ 0.000822 & (0.00123) & -0.00408^{*} & (0.00178) \\ -0.0537^{* * *} & (0.00532) & -0.0485^{* * *} & (0.00761) \\ -0.0378^{* * *} & (0.00603) & -0.0489^{* * *} & (0.00896) \\ 0.159^{* * *} & (0.00752) & 0.139^{* * *} & (0.0114) \\ 0.158^{* * *} & (0.0170) & 0.205^{* * *} & (0.0247) \\ 0.265^{* * *} & (0.0402) & 0.266^{* * *} & (0.0558) \\ & & & \\ -0.00488 & (0.0163) & -0.00134 & (0.0230) \\ 0.144^{* * *} & (0.0181) & 0.0658^{*} & (0.0268) \\ 0.0802^{* * *} & (0.0196) & 0.116^{* * *} & (0.0270) \\ & & & \end{array}$

Intertemporal averages and values at $t-1$

Socio-demographic characteristics

Single (t-1)

Couple (t-1)

Couple with children (t-1)

Monoparental Family (t-1)

Extended Family (t-1)

Economic characteristics

$\mathrm{Nb}$ of cattle $(\mathrm{t}-1)$

$\mathrm{Nb}$ of porks $(\mathrm{t}-1)$

$\mathrm{Nb}$ of goats $(\mathrm{t}-1)$

$\mathrm{Nb}$ of poultry (t-1)

Area owned (ia)

Share of crops in TI (ia)

Share of animal products in TI (ia)

Share of agricultural wage work in TI (ia)

Share of non agricultural activities in TI (ia)

Share of cash crops in TI(ia)

$\begin{array}{ccc} & & \text { base } \\ 0.0392 & (0.109) & 0.136 \\ 0.287^{* *} & (0.0939) & 0.215^{*} \\ 0.254^{*} & (0.0989) & 0.205^{*} \\ 0.141 & (0.0918) & 0.0697 \\ & & \\ -0.0118^{* * *} & (0.00212) & -0.00394 \\ -0.0336^{* * *} & (0.00878) & -0.0185^{*} \\ -0.000105 & (0.00328) & 0.00186 \\ -0.00228^{* *} & (0.000869) & -0.00332^{* *} \\ -0.000933^{* * *} & (0.000209) & -0.000970^{* * *} \\ 0.512^{* * *} & (0.0962) & 0.295^{*} \\ -0.583^{* * *} & (0.160) & 0.434^{*} \\ 1.622^{* * *} & (0.150) & 1.605^{* * *} \\ 0.588^{* * *} & (0.0879) & 0.262^{*} \\ -4.504^{* * *} & (0.360) & -2.001^{* * *}\end{array}$

(0.102)

$(0.0856)$

$(0.0942)$

(0.0843)

$(0.00214)$

$(0.00867)$

$(0.00310)$

$(0.00110)$

$(0.000162)$

$(0.135)$

(0.217)

$(0.234)$

$(0.124)$

(0.313) 


\begin{tabular}{|c|c|c|c|c|}
\hline $\begin{array}{l}\text { Net buyer (ia) } \\
\text { Year and year*area dummies } \\
\text { Basis poverty status equation }\end{array}$ & \multicolumn{4}{|c|}{ included } \\
\hline Change in hhd size (t-2 to t-1) & $0.102^{* * *}$ & $(0.00752)$ & $-0.101^{* * *}$ & $(0.00746)$ \\
\hline Change in hhd gender ( $\mathrm{t}-2$ to $\mathrm{t}-1$ ) & 0.0644 & $(0.0429)$ & -0.0691 & $(0.0420)$ \\
\hline Shock on fields (t-2) & $0.0953^{* * *}$ & $(0.0212)$ & $-0.0809^{* * *}$ & $(0.0208)$ \\
\hline \multicolumn{5}{|l|}{ Statistics } \\
\hline Number of observations & 27422 & & 27478 & \\
\hline Number of households & 9856 & & 9912 & \\
\hline Genuine state dependance (a) & & & 0,481 & \\
\hline$\rho(\mathrm{b})$ & 0.109 & & -0.192 & \\
\hline Critical probability associated to $\rho$ & 0.582 & & 0.328 & \\
\hline Log likelihood & -21135.4 & & -17637.0 & \\
\hline
\end{tabular}

Average partial effects, Standard errors in parentheses, ${ }^{*} p_{i} 0.05, * * p_{i} 0.01,{ }^{* * *} p_{i} 0.001$

(a) Sample mean of $P($ pit=1/pit-1=1)- $P($ pit=1/pit-1=0), (b) correlation between the error terms of main and selection equations Table 12: Average partial effects- Endogenous switching probit model,

ROR surveys, 1996-2006 